\title{
0 EDITOR'S CHOICE \\ No injuries, but plenty of pain? On the methodology for recording overuse symptoms in sports
}

\author{
R Bahr
}

Correspondence to:

Professor R Bahr, Oslo Sports

Trauma Research Center,

Norwegian School of Sport

Sciences, PO Box 4014, Ullevaal

Stadion, 0406 Oslo, Norway;

roald@nih.no

Accepted 8 October 2009

\section{ABSTRACT}

Overuse injuries may represent as much of a problem as do acute injuries in many sports. This paper reviews key concepts related to the methodology for recording overuse symptoms. Results from the FIVB Volleyball Injury Study were used to compare two different recording methods. The aim of this paper was to provide recommendations on how standardised methodology can be developed to quantify overuse injuries in surveillance studies. Using beach volleyball data, a "traditional" cohort study approach using a time-loss injury definition suggested that injury risk was very low. In contrast, the data from a survey of past and present pain problems in the shoulder, knees and low back demonstrated that these were prevalent. The following recommendations are made: (1) studies should be prospective, with continuous or serial measurements of symptoms; (2) valid and sensitive scoring instruments need to be developed to measure pain and other relevant symptoms; (3) prevalence and not incidence should be used to report injury risk; (4) severity should be measured based on functional level and not time loss from sports. In conclusion, new approaches are needed to develop more appropriate methodology to quantify overuse injuries in studies.

\section{CRITICAL ISSUES IN SPORTS INJURY PREVENTION RESEARCH-STUDY DESIGN AND INJURY DEFINITIONS}

The first step in the sequence of sports injury prevention research, as outlined by van Mechelen et al in 1992, ${ }^{1}$ is to describe the magnitude of the problem in terms of the frequency and severity of injuries. Typically, a cohort study is used, where a number of teams or athletes are followed prospectively for one season or longer. The second step is to map the causes of injuries, to identify their risk factors and mechanisms. Risk factors are typically also examined in cohort studies, where the characteristics of injured athletes can be compared with athletes without injury. ${ }^{2}$ The final step in the injury prevention sequence is to introduce measures that are likely to reduce the future risk and/or severity of sports injuries and document whether they are effective. From an epidemiological standpoint it is ideal to evaluate preventive measures via a randomised controlled trial.

However, regardless of the study design used, the ability to record and report the magnitude of injuries reliably is a critical factor across all stages of injury prevention research. To facilitate the comparison of data between studies from different sports and levels of performance, standard methods should be applied. In 2006, following informal discussions during the 1st World Congress on Sports Injury Prevention in Oslo in June 2005, the Fédération Internationale de Football Association Medical Assessment and Research Centre (FMARC) hosted an Injury Consensus Group comprising a range of experts involved in the study of football injuries. This resulted in a consensus statement published in 2006 aiming to establish definitions and methodology, implementation and reporting standards for studies of injuries in football and to provide the basis for studies of injuries in other team sports. ${ }^{3}$

In the consensus document, an injury was defined as "any physical complaint sustained by a player that results from a football match or football training, irrespective of the need for medical attention or time loss from football activities." 3 An injury that results in a player receiving medical attention is referred to as a "medical attention" injury, and an injury that results in a player being unable to take a full part in future football training or match play as a "time loss" injury. ${ }^{3}$ It is important to recognise that the consensus paper provides not one but three different injury definitions: "any physical complaint," "medical attention injury" and "time loss injury." The choice of injury definition will influence the rate of injury reported in studies, as players will not always seek medical attention for physical complaints, and even fewer cases will result in time-loss injuries. Therefore, it should be expected that a "physical complaint" definition will yield a higher injury rate than a "medical attention" definition, and with a "time loss" definition resulting in the lowest rate.

Based on the same framework, a similar statement has been published for injury recording in rugby union, taking into account some specific issues associated with that sport. ${ }^{4}$ Primarily, nonfatal catastrophic injuries were added as a third subgroup of reportable injuries, defined as "a brain or spinal cord injury that results in permanent (>12 months) severe functional disability." Moreover, in 2007, some members of the Injury Consensus Group outlined how to deal with the difficult issue of re-injury, recurrent injuries and exacerbations when reporting injury rates. ${ }^{5}$

The 2006 consensus document appears to have been generally accepted, and the definitions and principles outlined are in widespread use in many different sports, judging from the more than 70 citations the paper has received already. In reviewing these papers, it appears that-of the three injury definitions outlined in the consensus paper-the time-loss definition is the one most commonly used, almost without exception. There 
are probably several reasons for this. One is, as recognised in the consensus paper, that variations in medical support may create differences in the incidence of injury reported between studies. Physical complaints are common among athletes, and unless someone is available to examine athletes on a daily basis, many will go unrecorded. The medical attention definition is of course also highly dependent on the availability of medical support. Using the time-loss definition permits comparison of data at different levels of performance, as injuries can be recorded based on attendance records kept by the coach, a parent or even the players themselves. Second, some would argue that the timeloss definition captures the most relevant injuries, those that directly influence the ability to take part in practice and games. The design of a typical cohort study, where injuries and their severity are recorded based on player attendance, is shown in fig 1.

\section{METHODOLOGICAL CHALLENGES FOR STUDIES ON OVERUSE INJURIES}

One question which follows from this is how appropriate this methodology is if it is applied to sports with few acute, traumatic injuries but a preponderance of overuse injuries. In the 2006 consensus statement, a traumatic injury was defined as an injury resulting from a specific, identifiable event, and an overuse injury as one caused by repeated microtrauma without a single, identifiable event responsible for the injury. ${ }^{3}$ Others have included the term gradual onset in the definition of an overuse injury.

In most cases, it is easy to classify an injury as acute or overuse, but in some cases it may be less obvious. This is particularly true when the symptoms have a sudden onset, although the injury may actually be the result of a long-term process. For example, an athlete with a stress fracture in the foot will often report that the symptoms originated during a specific run, perhaps even from a specific step. This means that the injury could be classified as an acute injury. Nevertheless,

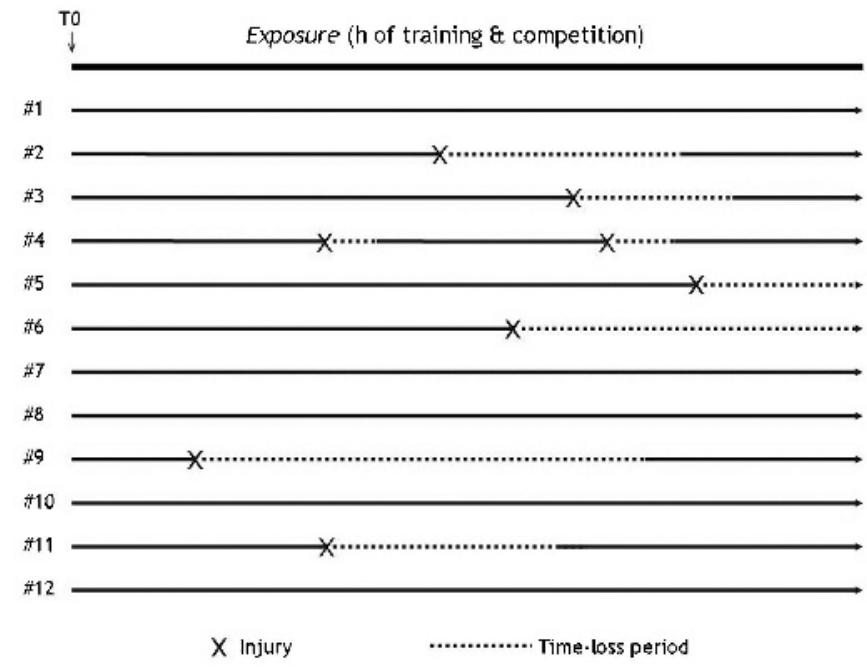

Figure 1 Example of a typical prospective cohort study design based on the time-loss definition, where 12 athletes have been followed for one season, suffering a total of eight injuries. The incidence of time-loss injuries can be calculated based on training and competition exposure, and the severity of each injury can be classified according to the duration of the time-loss period. The same principles are commonly employed in risk factor studies and intervention studies. the actual cause of the stress fracture is overuse over time. These types of injuries should be classified as overuse injuries.

As illustrated in fig 2, the pathological process is often under way for a period of time before the athlete notices the symptoms. It is believed that repetitive low-grade forces exceeding the tolerance of the tissues cause overuse injuries. In most cases, the tissue will repair without demonstrable clinical symptoms. However, if this process continues, the ability of the tissue to repair and adapt can be exceeded, resulting in a clinical overuse injury with symptoms. Note that although, in this example, the athlete did stop training and consulted the team physician, this is not always the case. Many overuse injuries are therefore not captured if a time-loss definition is used to record injuries.

Acute injuries are most common in sports in which the speed is high, and the risk of falling is great (eg, downhill skiing), and in team sports where there is much contact between players (eg, soccer and rugby union). Overuse injuries make up a large portion of injuries in aerobic sports that require long training sessions with a monotonous routine (eg, long-distance running, bicycling or cross-country skiing). But a large number of overuse injuries also occur in technical sports, in which the same movement is repeated numerous times (eg, tennis, javelin throwing, weightlifting and high jumping). However, the guidelines outlined in the consensus documents ${ }^{3}{ }^{4}$ were developed for football and rugby union; the question is how appropriate the recommendations are when applied to aerobic or technical sports where overuse injuries may be expected to dominate. A hypothetical scenario is shown in fig 3. This illustrates how-if a time loss injury definition is used-the injury rate may be recorded as low, despite a high prevalence of overuse injuries causing significant pain and reduced function.

This paper will use beach volleyball as an example of how different injury definitions and recording methods can lead to different conclusions regarding the rate and severity of overuse injuries over a defined time period. Beach volleyball is a technical sport with minimal contact between opposing players. Previous studies have shown that the injury risk, if defined as the incidence of acute time loss injuries, is low. The 2001 FIVB (Fédération Internationale de Volleyball) Beach Volleyball Injury Study showed that the incidence was 3.1 (SE 0.9) per 1000 competition hours and $0.8(0.2)$ per 1000 training hours

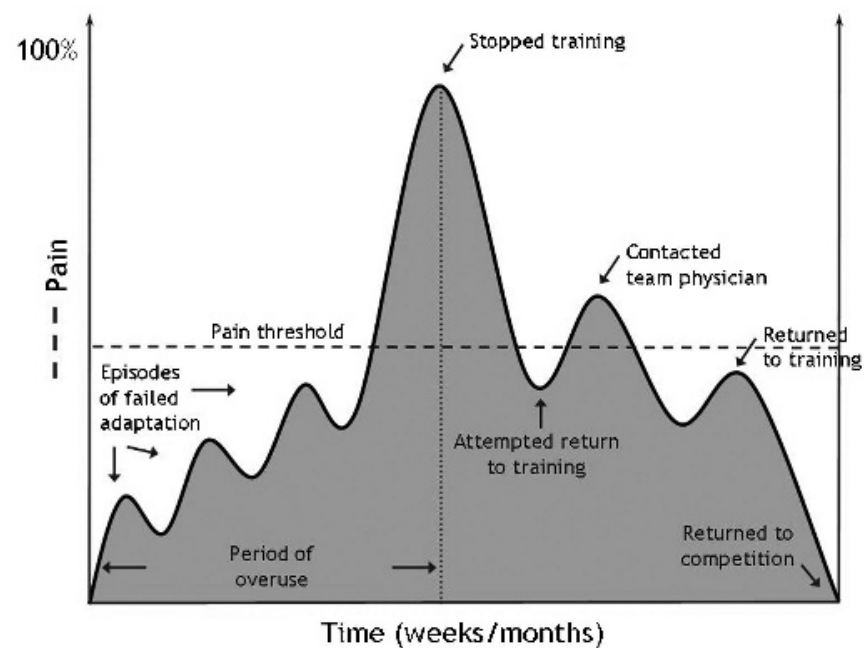

Figure 2 Hypothetical overview of the onset of tissue injury and pain in a typical overuse injury. Adapted from Leadbetter WB. Cell-matrix response in tendon injury. Clin Sports Med 1992;11:533-78. 


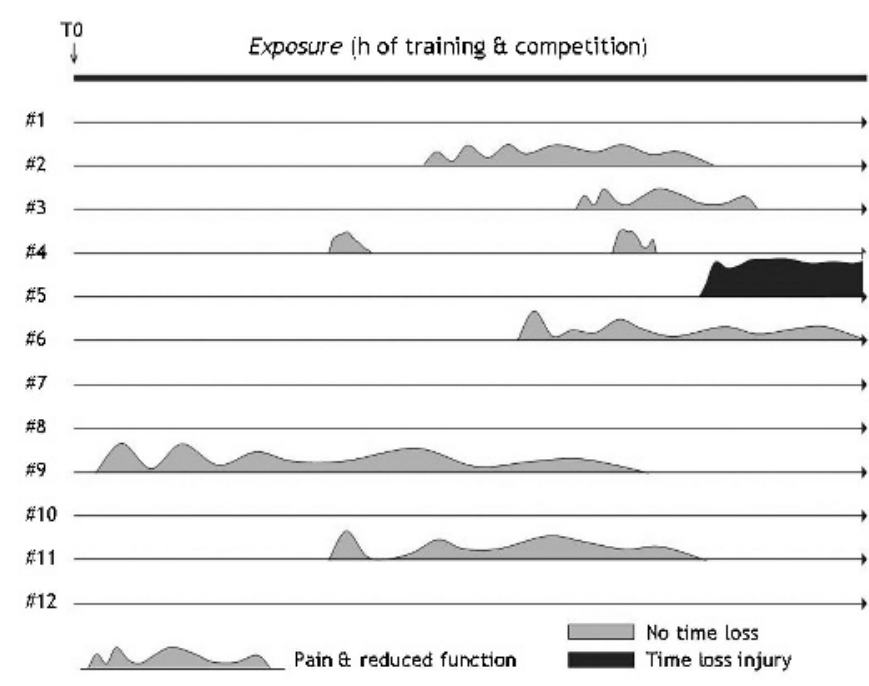

Figure 3 Hypothetical example of results from a prospective cohort study on symptoms of pain and reduced function among 12 athletes followed for one season. Although a total of eight episodes with significant symptoms can be observed, only one of these would have been detected if a time loss definition of injury had been used.

among players on the World Tour, the highest international professional level. ${ }^{6}$ This represents approximately $1 / 10$ th to $1 /$ 20th of the injury rate observed in professional football. ${ }^{78}$ The comparison is corroborated by data from the 2008 Beijing Olympic Games showing that beach volleyball ranks among the Olympic sports with the lowest injury risk. ${ }^{9}$

However, the FIVB Beach Volleyball Injury Study also showed that a significant number of athletes had sought medical attention for overuse injuries to the low back, shoulder and knees. ${ }^{6}$ In a cross-sectional study on the prevalence of jumper's knee in nine different sports, volleyball ranked highest with 44.6 (SD 6.6)\% of players reporting current symptoms. ${ }^{10}$ Based on their data, Lian et a l10 $^{10}$ concluded that the high prevalence, long duration of symptoms and low function scores suggested that in some sports, jumper's knee may cause at least as much impairment for athletic performance as do acute knee injuries. The prevalence of patellar tendinopathy among beach volleyball players is not known but is believed to be lower than the indoor game because the jumping and landing surface is soft. ${ }^{6}$

Thus, we compared the results from two different recording methods, one "traditional" injury registration using a time-loss injury definition and one survey of past and present pain problems in the shoulder, low back and knees (see box 1 for details on the data-collection methods). The aim of this paper is to (1) review common definitions used in sports injury research, (2) highlight the need to define overuse injuries differently from acute injuries for surveillance purposes and (3) provide ideas and recommendations on how standardised methodology can be developed to quantify overuse injuries in surveillance studies. The example of beach volleyball is used, but the principles apply to any sport where overuse injuries are common.

\section{CASE OF BEACH VOLLEYBALL}

\section{Retrospective injury registration}

A total of 26 time-loss injuries were reported during the 8-week competition period. Of these, 14 were acute injuries and 11 overuse injuries (one other; neck pain). Of the 115 players interviewed, $23(20 \%)$ reported one or more time-loss injuries during this period, 13 for acute injuries and 10 for overuse injuries. The incidence of acute time-loss injuries was 4.1 (SE 1.3) per 1000 competition hours and $0.5(0.2)$ per 1000 training hours. The injury rate was higher during matches than during training (relative risk: 9.0; $<<0.001$ ), but there was no gender difference in total injury rate, nor for beach volleyball competition or training, warm-up or other training.

Of the 26 time-loss injuries, knee injuries $(n=5,36 \%)$ were the most common acute injuries and shoulder injuries $(n=5$, $42 \%)$ the most common overuse injuries.

The severity of the time-loss injuries reported was mild, as judged by the duration of absence from match/training. Only two injuries (one acute and one overuse) resulted in an absence of more than 3 weeks, four injuries resulted in 8-21 days of absence, four injuries resulted in 4-7 days and the majority, 16 injuries, resulted in 1-3 days of time loss.

\section{Survey of pain problems in the low back, shoulder and knee}

The distribution of responses to the questionnaire about low back, shoulder and knee pain is detailed in table 1. The results show that as many as one-third of the players reported symptoms from at least one region during the previous 7 days, and up to one half during the previous 2 months. When they were asked to rate their pain level on a $10 \mathrm{~cm}$ visual analogy scale, players who had experienced pain problems during the previous 2 months rated their current pain level while playing volleyball at 2.4 (SD 2.0) for the low back and 3.7 (2.1) for the shoulder. Players reporting to have had symptoms of jumper's knee during the past 2 months reported their current VISA score at 77 (18). Despite this, few players reported to have missed training altogether, and even fewer reported having missed tournaments during the same period (table 1).

A total of 56 players (49\%) reported pain problems from one region (low back, shoulder or knees) during the past 2 months, 32 players (28\%) from two regions and seven players $(6 \%)$ from all three regions (fig 4). Only 20 players (17\%) reported no pain problems from any of these three regions during the previous 2 months. For the past 7 days, 48 players $(42 \%)$ reported pain problems from one region, 22 players $(19 \%)$ from two regions and four players (3\%) from all three regions (fig 4), while 41 players $(36 \%)$ reported no pain from any of these three regions during the previous week.

\section{COMPARING DATA FROM THE TWO DIFFERENT RECORDING METHODS; NO INJURIES BUT PLENTY OF PAIN?}

As expected, the data show that the injury definition and datacollection method used play important roles in determining the magnitude of injuries in a technical sport such as beach volleyball. A tentative conclusion based on the "traditional" cohort study approach using a time-loss injury definition would be that the injury risk is very low. In contrast, the data from the survey suggest that pain problems are prevalent, predominantly resulting from overuse injuries in the shoulder, knees and low back.

A key limitation of the injury registration is that this was retrospective, asking the players to recall injuries over an 8-week period. However, although retrospective injuries are prone to recall bias, prospective registration does not always result in more complete data, as shown in a recent study among World Cup skiers and snowboarders. ${ }^{11}$ In fact, the FIVB Volleyball Injury Study I from 2001 showed that retrospective injury recall and prospective registration by tournament medical staff yielded very similar injury rates, 2.5 time-loss injuries per 
Table 1 Responses (\%) to the various questions related to pain problems in the low back, shoulder (dominant side only) and knees ("jumper's knee" only) for women $(n=58)$ and men $(n=57)$

\begin{tabular}{|c|c|c|c|c|c|c|}
\hline \multirow[b]{2}{*}{ Question } & \multicolumn{2}{|c|}{ Low back pain } & \multicolumn{2}{|c|}{ Shoulder pain } & \multicolumn{2}{|l|}{ Knee pain } \\
\hline & Women & Men & Women & Men & Women & Men \\
\hline Pain previous 2 months & $23(40 \%)$ & $26(46 \%)$ & $33(57 \%)$ & $22(39 \%)$ & $14(24 \%)$ & $23(40 \%)$ \\
\hline Pain previous 7 days & $13(22 \%)$ & $18(32 \%)$ & $25(43 \%)$ & $15(26 \%)$ & $11(19 \%)$ & $22(39 \%)$ \\
\hline \multicolumn{7}{|l|}{ Days of missed training } \\
\hline 0 & 46 (79\%) & $54(95 \%)$ & $45(78 \%)$ & $43(75 \%)$ & $52(90 \%)$ & $43(75 \%)$ \\
\hline $1-7$ & $11(19 \%)$ & $2(4 \%)$ & $11(19 \%)$ & $11(19 \%)$ & $3(5 \%)$ & $9(16 \%)$ \\
\hline $8-30$ & $1(2 \%)$ & $1(2 \%)$ & $2(3 \%)$ & $2(4 \%)$ & $2(3 \%)$ & $4(7 \%)$ \\
\hline$>30$ & 0 & 0 & 0 & 0 & $1(2 \%)$ & $1(2 \%)$ \\
\hline \multicolumn{7}{|l|}{ Tournaments missed } \\
\hline None & $57(98 \%)$ & $54(95 \%)$ & $54(93 \%)$ & $53(93 \%)$ & $57(98 \%)$ & $53(93 \%)$ \\
\hline $1-3$ & $1(2 \%)$ & $2(4 \%)$ & $3(5 \%)$ & $4(7 \%)$ & $1(2 \%)$ & $4(7 \%)$ \\
\hline $4-10$ & 0 & 0 & $1(2 \%)$ & 0 & 0 & 0 \\
\hline$>10$ & 0 & $1(2 \%)$ & 0 & 0 & 0 & 0 \\
\hline \multicolumn{7}{|c|}{$\begin{array}{l}\text { Taking painkillers or anti-inflammatory } \\
\text { medication when playing? }\end{array}$} \\
\hline Yes & $4(7 \%)$ & $6(11 \%)$ & $9(16 \%)$ & 7 (12\%) & $6(10 \%)$ & $4(7 \%)$ \\
\hline
\end{tabular}

1000 h of competition in the prospective study versus 3.1 in the retrospective study. ${ }^{6}$ To minimise recall bias, we limited the recall period to 8 weeks and used a structured interview format in which the ability to recall injuries, training and competition history seemed to be greatly improved by their connection to specific weekly tournaments and locations. ${ }^{11}{ }^{12}$ We therefore believe that the low incidence of time loss injuries recorded, approximately 4 injuries per $1000 \mathrm{~h}$ of match play and $<1$ injury per 1000 training hours, represent reasonable estimates. Another important limitation of this study design is that serious, season-ending injuries, for example, anterior cruciate ligament injuries, were not recorded. Teams that had to withdraw from competition because of injury before the start of the Gstaad tournament were not available for interview. Consequently, the injury rates observed probably represent an underestimation of the true injury incidence. We know of individual cases where World Tour participants suffered seasonending injuries during the 8-week study period, including serious knee injuries. However, these were few. Consequently, there is no doubt that the incidence of acute injuries is considerably lower in beach volleyball than contact team sports, such as basketball, football, team handball or ice hockey. ${ }^{9}{ }^{13}$

In contrast, the pain survey revealed that players reported a host of pain problems related to the low back, knees or dominant shoulder. In fact, more than a third of the players reported pain problems from at least two regions during the previous 2 months. Only $17 \%$ of players reported having experienced no pain problems from any of the three regions during the previous 2 months; the corresponding figure for the past 7 days was also low, only 36\% (fig 4). Despite this, few players reported to have missed training or competition during the study period, and very few overuse injuries were also identified in the injury registration which caused more than a few days of time loss. In most cases, the pain levels reported were moderate, 2.4 for the low back and 3.7 for the shoulder on a $0-10$ visual analogue scale.

The pain survey represents a fundamentally different approach to the injury registration, in that players are asked
Figure 4 Venn diagrams depicting the number of players reporting pain problems in each of the three regions during the previous 2 months (left panel) and 7 days (right panel).

\section{Previous 2 months (no pain problems reported: $n=20$ )}

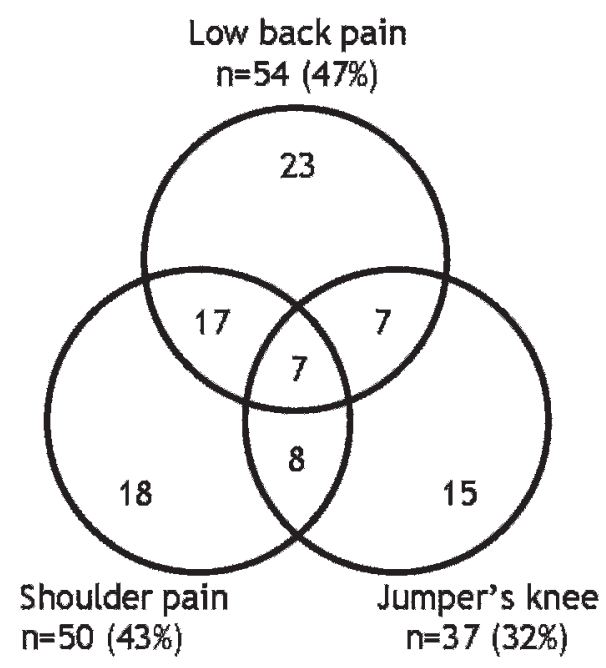

\section{Previous 7 days (no pain problems reported: $n=41$ )}

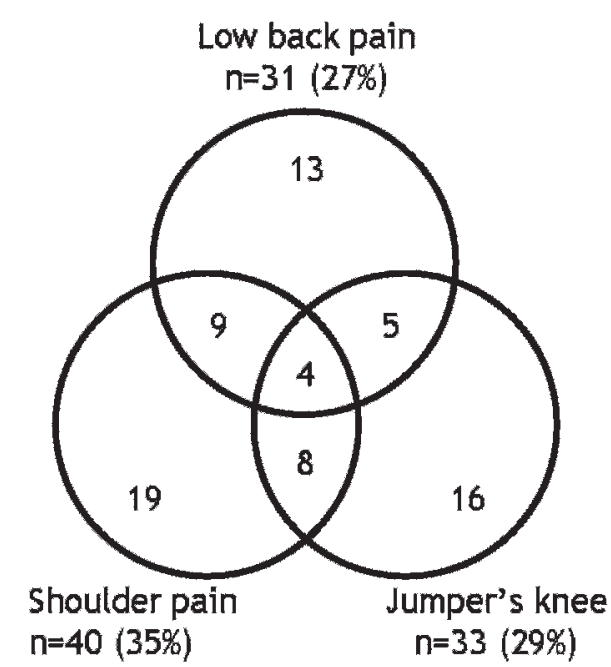


to recall pain problems, regardless of their effect on participation and performance. This can be likened to the "any physical complaint" definition from the 2006 consensus paper. However, it should be noted that the questions were limited to "pain, ache or soreness;" other functional limitations which could represent a physical complaint were not recorded. The questionnaires were limited to three locations predicted to cause problems in this group of athletes, that is the low back, shoulder and knees. These regions were identified based on clinical experience as well as the 2001 FIVB Injury Study, where overuse injuries were reported mainly from these three regions. ${ }^{6}$ Questions relating to other regions, such as fingers, elbow, the cervical spine or other knee problems than those caused by jumper's knee, would probably have resulted in some, albeit fewer problems reported than for the main predilection sites among volleyball players.

Another fundamental difference between the beach volleyball study and most previous studies is that the present study focused on symptoms, and not on identifying specific injuries. In fact, the underlying diagnosis was not known, except for knee problems, which was limited to those caused by jumper's knee. One consequence is that we do not necessarily know that the symptoms result from overuse injuries; low back pain is common in the non-athletic population, as well.

The same limitations apply to the pain survey as the injury registration, recall and selection biases. Recall bias-especially related to the 12- and 2-month questions-can be expected to be higher than for time-loss injuries. Players with overuse problems may have been less likely to enter the Gstaad tournament than the previous tournaments on the tour. The Gstaad event was the last tournament before the Olympic Games but did not count towards the Olympic ranking, which may have led some to stay home to rehab before the Beijing Games. In other words, as for the time-loss injuries, the data presented on pain problems can be expected to represent minimum estimates.

Another limitation of the pain survey is that there are no validated instruments for the specific purpose of evaluating the level of physical complaints among athletes. We used a questionnaire which was originally developed to study the prevalence of occupational musculoskeletal symptoms ${ }^{14}{ }^{15}$ and later adapted to study the prevalence of low back pain among athletes. ${ }^{16}$ We then used the same questions to assess shoulder and knee pain. However, these are not designed to measure functional limitations experienced by the players; nor are they able to capture the level of pain players have experienced over the course of a season. The exception may be the VISA form, which does measure pain levels during several different functional tasks and to a certain extent also detects limited performance among players who are still competing and training.

Despite these limitations, it appears safe to conclude that the injury definition and data-collection methods are critically important in determining the magnitude of injuries in a surveillance study. Using a "traditional" cohort study approach with a time-loss injury definition, it seems that the injury risk in beach volleyball is very low, while the pain survey suggests that most players are affected by pain problems from overuse injuries in the shoulder, knees or low back.

\section{RECOMMENDATIONS ON METHODOLOGY TO QUANTIFY OVERUSE INJURIES IN SURVEILLANCE STUDIES}

Based on our experience from beach volleyball, it seems clear that a novel approach is needed to be able to quantify the problem of overuse injuries among athletes. This is particularly important in sports where overuse injuries are expected to dominate, that is aerobic sports and technical sports, if we are to present a valid representation of the injury problem. However, it is also possible that the magnitude of overuse injuries and complaints in high-speed and contact sports is underestimated when the traditional methodology with a time-loss definition is used to record injuries.

The following recommendations are made.

\section{Studies should be prospective-with continuous or serial measurements}

In the example from beach volleyball, the prevalence of pain problems was measured retrospectively in active players during one specific event. A similar approach has been used in previous cross-sectional studies. ${ }^{1016}$ The main limitations of this approach have been addressed above, mainly recall and selection biases. To minimise these, we suggest that a prospective study design is used as illustrated in fig 5, following a predefined group of athletes with serial measurements of symptoms and function. Ideally, symptoms should be monitored continuously, but in most cases this is not possible for practical reasons. A more realistic approach is to assess the current level of symptoms at regular intervals-for example, once a week or once a month. The frequency would depend on how much symptoms are expected to fluctuate and the duration and size of the study. The same principles should be applied not just in phase 1 studies on injury magnitude, but also in cohort studies on risk factors and intervention studies. Note that if the symptoms recorded are prevalent in the general population it may be necessary to include non-athletic or other relevant control groups in studies. Otherwise, it will not be possible to attribute the symptoms observed to athletic participation.

Valid and sensitive scoring instruments need to be developed The objective is to detect what is referred to as "any physical complaint" that results from sports participation. Pain may be regarded as the main symptom of overuse injuries. However, pain is not the only symptom, and other domains of

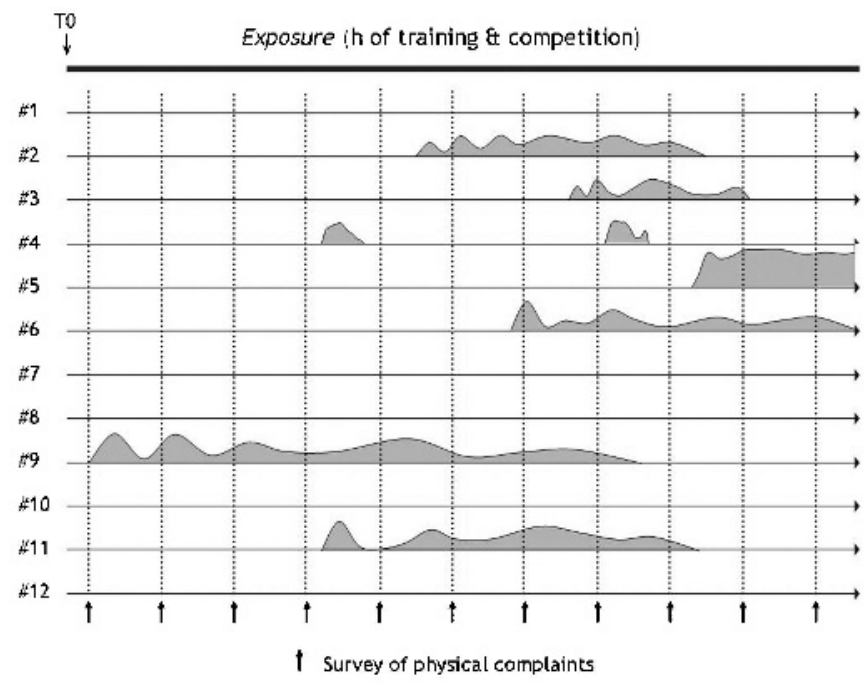

Figure 5 Schematic of possible prospective cohort study to assess physical complaints in a cohort of athletes. The vertical dotted lines and arrows denote periodical surveys where each athlete scores his level of pain problems, functional limitations and any performance effects from overuse injuries. 


\section{FIVB Injury Study II}

The data were collected as part of the FIVB Injury Study II during the FIVB World Tour Grand Slam tournament in Gstaad, Switzerland from 21 July to 27 July 2008. The first part of the study consisted of a retrospective registration of all injuries incurred from 26 May to 20 July, that is until the start of the event in Gstaad. The second part of the study consisted of a self-completion survey covering past and present pain problems to the low back, shoulder and knees.

The players were informed about the purposes and requirements of participation in the study during the technical meeting, which all the teams were required to attend. They were invited to contact the research group for a 15-20 min interview at a time suitable for them, and they were informed that participation was voluntary. They were also assured that the information provided could not be traced back to the individual, team or country. Care was taken not to disturb the athletes in their preparation for matches or during recovery.

Among the 128 players qualified for the main draw, a total of 115 players consented to take part in the study ( 58 of 64 female players and 57 of 64 male players; overall response rate $90 \%$ ).

\section{Retrospective injury registration}

The format of the retrospective injury registration was personal interviews with the players, where they were first asked to recall their exposure during the previous 2-month period (all tournaments played and training volume, beach volleyball and fitness training) based on a structured form based on the week-by-week competition calendar for the World Tour season for men and women, respectively. They were then interviewed about any new or recurrent injuries identified during this period.

The injury registration period covered 8 weeks of training and competition. During this period, seven tournaments for women and men were held on the World Tour, and players may also have participated in other national or regional tournaments. The World Tour tournaments were formatted either as a 32-team double elimination bracket or with an initial pool play phase followed by a single elimination bracket. A team could play between two and eight matches in the main tournament each week. In addition, before the main draw of each tournament a 2day qualification tournament was played in which 30-50 teams competed for eight spots in the main draw. The average duration of matches as recorded on the score sheets from the FIVB World Tour tournaments in question was 50 min for men and 44 min for women (range 28 to $93 \mathrm{~min})$.

The injury definition used for this part of the study was "any injury causing cessation of the athlete's participation in competition or training for at least 1 day following the onset of injury." For each injury the player had sustained, the following information was collected: (1) type of activity (whether the injury occurred in a match, during warm-up for a match, during beach volleyball training, or during strength training or other conditioning training); (2) whether it was an acute injury (with a sudden onset) or an overuse injury (with a gradual onset); (3) injury type (concussion, contusion, sprain, strain, tendinopathy, dislocation, fracture, skin wound, other); and (4) injured body region. Also, the time to return to play was recorded as the time it took until the athlete was fully able to participate in matches and comply with all instructions given by the coach during training.

Exposure was recorded retrospectively for each week, including the number of matches played (including qualification matches for a World Tour event main draw, or participation in other non-World Tour events), the number of hours of beach volleyball training and other forms of training (strength and conditioning). The total exposure was estimated based on the average match duration on the World Tour (see above) at $2422 \mathrm{~h}$ of competition and $8710 \mathrm{~h}$ of training.

\section{Survey on pain problems}

The second part of the study was a self-completion questionnaire focusing on overuse problems in the low back, dominant shoulder and knees (jumper's knee, patellar tendinopathy). The questionnaire was developed form a previous study on low back pain problems in rowing, orienteering and cross-country skiing based on standardised Nordic questionnaires that had been developed and validated to study the prevalence of occupational musculoskeletal symptoms. ${ }^{14}{ }^{15}$ This questionnaire includes questions on low back pain (defined as "pain, ache or soreness in the low back, with or without radiating pain to the gluteal area or the lower extremity"). The form also includes a full-figure outline of the posterior body where the low back was shown as a hatched area covering the lumbar region. Based on this form, similar questionnaires were developed asking about shoulder pain (defined as "pain, ache or soreness in the dominant shoulder, with or without radiating pain to the upper extremity") and knee pain (defined as "pain, ache or soreness in the quadriceps and/or patellar tendon"). In other words, each player completed three similar questionnaires, one for each region. The definitions of low back and shoulder pain were shown prominently on the first page of each questionnaire, while the concept of patellar/quadriceps tendon pain was explained by pointing to and palpating the relevant tendon regions before the athletes began completing the questionnaires.

The standard questions based on the Nordic questionnaire included the following:

- Have you experienced low back/shoulder/knee pain during the previous 2 months?

- Have you experienced low back/shoulder/knee pain during the previous 7 days?

- How many days of training have you missed because of low back/shoulder/knee pain during the past 12 months?

- How many tournaments have you missed because of low back/shoulder/knee pain during the past month?

- Do you currently take pain killers or anti-inflammatory medication when you play because of shoulder pain?

- If you do have shoulder pain while playing, how intense is the pain usually? Please indicate by placing $X$ on the line below $(10 \mathrm{~cm}$ visual analogue scale from "No pain" (0) to "Worst pain possible" (10)0.

In addition, players were asked to self-record their Victorian Institute of Sport Assessment (VISA) scores for both knees. ${ }^{21}$ This is a validated pain and function index with a high score of 100 (no symptoms) and low score of 0 (maximum symptoms) that has been developed specifically for this purpose and has been shown to be a valid measure of symptoms. ${ }^{21}$ 
impairment and disability should be included if the goal is to describe the consequences experienced by the athlete. Depending on the injury location, other problems could include swelling, instability, reduced strength, limited range of motion, reduced agility and other functional limitations affecting athletic performance. In health research, questionnaires have been developed to measure health-related quality of life using multidimensional outcome measures that include domains of physical, mental and social health and measures of function and disability. For example, a variety of different joint-specific scoring instruments have been developed for the knee (eg, the Knee injury and Osteoarthritis Outcome Score (KOOS), ${ }^{17}$ International Knee Documentation Committee (IKDC), ${ }^{18}$ the shoulder (eg, Constant Murley Score (CMS), ${ }^{19}$ American Shoulder and Elbow Surgeons evaluation form (ASES) ${ }^{20}$ and a number of other joints and regions. However, most scoring instruments have been developed to assess treatment outcomes in non-athletic patient populations. Although they may have been shown to be valid, reproducible and sensitive in this setting, their use cannot necessarily be extended to the monitoring of overuse injuries in athletes. It is likely that new instruments need to be developed for this specific purpose. Whether these need to be specific to each region or joint remains to be seen, perhaps it will be possible to develop general scoring instruments to measure the level of pain and functional limitations experienced by athletes. Regardless, scoring instruments should be completed by the athletes themselves, and developing internet-based solutions and perhaps even methods based on text messaging could make it easier and more convenient to participate in studies.

\section{Prevalence and not incidence should be used to report injury risk} The "traditional" measure of injury risk is incidence, the number of new cases during a specific period of exposure. However, overuse injuries and pain problems such as low back pain and jumper's knee are often chronic, with periods of remission and exacerbation. For example, Lian et al ${ }^{10}$ showed that $44 \%$ of volleyball players were affected by jumper's knee. However, their data also showed that the average duration of symptoms for athletes with jumper's knee was 32 months, and only $25 \%$ had developed the condition during the same season. Therefore, prevalence, the proportion of athletes affected by problems at any given time, is a more appropriate measure of the magnitude of injuries than incidence. With serial measurements, it should be possible to report, for example, average values over the course of the season and even compare different stages of the season.

\section{Severity should be measured based on functional level and not time loss from sports}

As illustrated by the beach volleyball data presented above, the duration of time loss from sports is not an appropriate measure of injury severity. If valid and sensitive scoring instruments can be developed, it should be possible to express the functional level or performance limitation of an athlete in relation to full function. For example, although the limitations of the VISA score have been addressed above, this scoring instrument is an example of how function can be scored from $100 \%$ to $0 \%$.

It should be noted that there are no fundamental differences between these recommendations and those presented in the consensus statement on injury recording in football. ${ }^{3}$ Rather, the present guidelines represent an extension of these, with a particular focus on how these could be applied when the purpose is to study overuse injuries in sports.

In conclusion, new evidence suggests that overuse injuries may represent as much of a problem in many sports as do acute injuries. New approaches are needed to develop more appropriate methodology to quantify overuse injuries in studies across all phases of injury prevention research.

Acknowledgements: I am indebted to WW Briner Jr and MA Bahr, for their collaboration in the FIVB Volleyball Injury Study II, to the FIVB, for financial support, and to FIVB staff and officials, for practical support during all phases of the study.

Funding: The Oslo Sports Trauma Research Center has been established at the Norwegian School of Sport Sciences through generous grants from the Royal Norwegian Ministry of Culture, the Eastern Norway Regional Health Authority, Norsk Tipping AS and the Norwegian Olympic Committee \& Confederation of Sport.

Competing interests: None.

Provenance and peer review: not commissioned; externally peer reviewed

\section{REFERENCES}

1. van Mechelen W, Hlobil H, Kemper HC. Incidence, severity, aetiology and prevention of sports injuries. A review of concepts. Sports Med 1992:14:82-99.

2. Bahr R, Holme I. Risk factors for sports injuries - a methodological approach. Br J Sports Med 2003;37:384-92.

3. Fuller CW, Ekstrand J, Junge A, et al. Consensus statement on injury definitions and data collection procedures in studies of football (soccer) injuries. Br J Sports Med 2006;40:193-201.

4. Fuller CW, Molloy MG, Bagate C, et al. Consensus statement on injury definitions and data collection procedures for studies of injuries in rugby union. Br J Sports Med 2007:41:328-31.

5. Fuller CW, Bahr R, Dick RW, et al. A framework for recording recurrences, reinjuries, and exacerbations in injury surveillance. Clin J Sport Med 2007:17:197-200.

6. Bahr R, Reeser JC. Injuries among world-class professional beach volleyball players. The Federation Internationale de Volleyball beach volleyball injury study. Am J Sports Med 2003:31:119-25.

7. Dvorak J, Junge A, Grimm K, et al. Medical report from the 2006 FIFA World Cup Germany. Br J Sports Med 2007;41:578-81.

8. Walden M, Hagglund M, Ekstrand J. UEFA Champions League study: a prospective study of injuries in professional football during the 2001-2002 season. Br J Sports Med 2005;39:542-6.

9. Junge A, Langevoort $\mathrm{G}$, Pipe $A$, et al. Injuries in team sport tournaments during the 2004 Olympic Games. Am J Sports Med 2006;34:565-76.

10. Lian $\boldsymbol{\emptyset}$, Engebretsen L, Bahr R. Prevalence of jumper's knee among elite athletes from different sports: A cross-sectional study. Am J Sports Med 2005:33:561-7.

11. Flørenes TW, Nordsletten L, Heir S, et al. Recording injuries among elite skiers and snowboarders - a methodological study. Scand J Med Sci Sports. In press.

12. Bjørneboe J, Flørenes TW, Bahr R, et al. Validation of injury surveillance in male professional football. Scand J Med Sci Sports. In press.

13. Bahr R, van Mechelen W, Kannus P. Prevention of sports injuries. In: Kjaer M, ed Scandinavian textbook of sports medicine. Copenhagen: Munksgaard, 2002:299-314.

14. Andersson G, Biering-Sørensen F, Hermansen L, et al. Nordiska frågeformulär för kartleggning av yrkesrelaterade muskuloskeletala besvär. Nord Med 1984:99:54-5.

15. Kuorinka I, Jonsson B, Kilbom $\AA$, et al. Standardised Nordic questionnaires for the analysis of musculoskeletal symptoms. App/ Ergon 1987;18:233-7.

16. Bahr R, Andersen SO, Loken S, et al. Low back pain among endurance athletes with and without specific back loading - a cross-sectional survey of cross-country skiers, rowers, orienteerers, and nonathletic controls. Spine 2004:29:449-54.

17. Roos EM, Roos HP, Lohmander LS, et al. Knee Injury and Osteoarthritis Outcome Score (KOOS) - development of a self-administered outcome measure. J Orthop Sports Phys Ther 1998;28:88-96.

18. Irrgang JJ, Anderson AF, Boland AL, et al. Development and validation of the international knee documentation committee subjective knee form. Am J Sports Med 2001:29:600-13

19. Constant CR, Murley AH. A clinical method of functional assessment of the shoulder. Clin Orthop Relat Res 1987:214:160-4.

20. King GJ, Richards RR, Zuckerman JD, et al. A standardized method for assessment of elbow function. Research Committee, American Shoulder and Elbow Surgeons. J Shoulder Elbow Surg 1999:8:351-4.

21. Visentini PJ, Khan KM, Cook JL, et al. The VISA score: an index of severity of symptoms in patients with jumper's knee (patellar tendinosis). Victorian Institute of Sport Tendon Study Group. J Sci Med Sport 1998:1:22-8. 


\title{
Identifying context-specific competencies required by community Australian Football sports trainers
}

\author{
Alex Donaldson, Caroline F Finch
}

Australian Centre for Research into Injury in Sport and its Prevention (ACRISP), Monash Injury Research Institute (MIRI), Monash University, Clayton, Victoria, Australia

\section{Correspondence to}

Dr Alex Donaldson, Room 315,

Building 70, Clayton Campus, Monash University, Clayton,

VIC 3800, Australia;

alex.donaldson@monash.edu

Accepted 30 August 2011

Published Online First

6 October 2011

\section{ABSTRACT}

Background First-aid is a recommended injury prevention and risk management strategy in community sport; however, little is known about the sport-specific competencies required by first-aid providers.

Objective To achieve expert consensus on the competencies required by community Australian Football (community-AF) sports trainers.

Study design A three-round online Delphi process.

Setting Community-AF.

Participants 16 Australian sports first-aid and community-AF experts.

Outcome measures Rating of competencies as either 'essential', 'expected', 'ideal' or 'not required'.

Results After Round 3, 47 of the 77 (61\%) competencies were endorsed as 'essential' or 'expected' for a sports trainer to effectively perform the activities required to the standards expected at a community-AF club by $\geq 75 \%$ of experts. These competencies covered: the role of the sports trainer; the responsibilities of the sports trainer; emergency management; injury and illness assessment and immediate management; taping; and injury prevention and risk management. Four competencies (5\%) were endorsed as 'ideal' or 'not required' by $\geq 85 \%$ of experts and were excluded from further consideration. The 26 competencies where consensus was not reached were retained as secondtier, optional competencies.

Conclusions Sports trainers are important members of on-field first-aid teams, providing support to both injured players and other sports medicine professionals. The competencies identified in this study provide the basis of a proposed two-tiered community-AF-specific sports trainer education structure that can be implemented by the peak sports body. This includes six mandatory modules, relating to the 'required' competencies, and a further six optional modules covering competencies on which consensus was not reached.

\section{INTRODUCTION}

It is now widely accepted that injuries, including serious ones, can occur during participation in community Australian Football (community$\mathrm{AF})^{1-3}$ and that injury prevention strategies, including the provision of appropriate first-aid, should be adopted. ${ }^{4}{ }^{5}$ Previous studies have described the first-aid policies and associated practices of community-AF clubs ${ }^{6}$ and other Australian community sports clubs. ${ }^{8-10}$ Internationally, the qualifications, experience or knowledge of firstaid providers have been described across a range of sports and settings. ${ }^{11-13}$

First-aid providers are an important component of on-field injury management teams, providing support to both injured players and other sports medicine professionals. However, to our knowledge, no studies have been published in the peer-reviewed literature reporting the specific competencies - defined as the knowledge, skills and attitudes needed to effectively perform the activities required to the standards expected required for first-aid providers in any community sport setting.

The Australian Football League (AFL), the national governing body for AF, considers sports trainers (ie, first-aid providers) part of the fabric of every club and that they play a key role in player preparation and safety at all levels. However, community-AF clubs, like their counterparts in other sports, have experienced considerable difficulty in recruiting and retaining suitably competent sports trainers. ${ }^{67}$ The AFL believes that the lack of community-AFspecific relevance of the currently available sports trainer education courses is a key factor contributing to this difficulty. As a consequence, the AFL also believes that potential community-AF sports trainers are reluctant to attend currently available education courses because they are perceived as time consuming, costly, including/focusing too much on some irrelevant content and not including/focusing enough on some relevant content. This article identifies the competencies that experts agree are required by community-AF sports trainers and proposes a community-AF-specific competency-based sports trainer education structure.

\section{METHODS}

A Delphi technique ${ }^{14}$ was used to reach consensus among a panel of experts without engaging them in direct discussions. ${ }^{15}$ The Delphi technique is an anonymous process where experts communicate their opinions and knowledge, see how their evaluation of the issue aligns with others and reconsider and change their opinions, if desired, after viewing the findings of the group's deliberations. ${ }^{16}$ One advantage of the Delphi technique over other forms of consensus building (eg, committee meetings or focus group discussions) is that participants cannot be intimidated or inhibited from expressing their views by the presence of stronger or more hierarchically senior individuals who can dominate direct discussions. ${ }^{17}$ The major disadvantage of the indirect Delphi communication process is that participants cannot question or request further information or clarification from each other.

The University of Ballarat Human Research Ethics Committee approved the study protocol, which adhered to the fundamental Delphi 
principles of providing feedback to participants between rounds while maintaining the anonymity of participants.

\section{Expert panel formation}

The project team (comprising both authors, two community-AF administrators, an AF-specialist sports physician and an AF-specialist physiotherapist) identified a panel of 18 people from across Australia whom they believed had sufficient current involvement, experience, qualifications and knowledge in community-AF and sports trainer-related activities to be considered 'experts'. These experts were initially informed about the study through an email from an AFL representative and recruited through a subsequent email invitation from a member of the research team.

The 16 experts who agreed to participate in the study included seven community football administrators; six sports trainers or medical officers in community-AF; two sports trainer educators; and one parent/coach. To confirm their expertise, the 16 panel members completed an online background questionnaire including items about their age and gender and 10 five-point scales (none, a little, some, a lot, very extensive) to self-rate their current involvement, experience, qualifications, knowledge and overall expertise in community-AF and sports trainer-related activities.

\section{Questionnaire development and administration}

For all three Delphi rounds, questionnaires were developed using SurveyMonkey software (http://www.surveymonkey. com), and panel members were emailed the hyperlink to the online questionnaire. Panel members were given up to 14 days to complete each questionnaire, and non-responders were sent up to two email reminders. There was a break of approximately 2 weeks between each round, and the whole process was conducted between August and October 2009.

\section{Round 1}

Round 1 of the Delphi was used to identify all the competencies that community-AF sports trainers should have in an 'ideal world'. An initial list of 74 competencies - organised into seven categories: role and importance (4 competencies); responsibilities (10); emergency management procedures and responses (5); injury and illness assessment and management (26); taping (5); injury prevention and risk management (16); and health promotion (8) - was developed based on: (1) a review of the nature and site of injuries to community-AF players; (2) current content of the Sports Medicine Australia and the Australian Rugby League sports first-aid/sports trainer education courses; and (3) the project team's expertise. Panel members were asked to: decide if, and how, each competency should be changed; comment generally on each competency; and suggest additional competencies. They were informed that their comments would be shared anonymously, through a summary report of the results of Round 1, with the panel during Round 2. The information gathered in Round 1 was collated and reviewed, and suggested changes/additions were included, if agreed as relevant by the members of the project team, in a revised list for Round 2.

\section{Round 2}

In Round 2, a revised list of 77 competencies within the same categories was circulated to the panel members who were asked to rate each competency as either:

- ESSENTIAL - all qualified sports trainers must have this competency and no community-AF practice/training or match can go ahead unless someone with this competency is present.

- EXPECTED - all qualified sports trainers should have this competency.

- IDEAL - in an ideal world where money, time and other resources are unlimited, it would be good if a qualified sports trainer had this competency.

- NOT REQUIRED - if a sports trainer had this competency it would be of no value or use to the individual trainer or to the club/players they provide services to.

Panel members were encouraged to explain why they had given a competency a particular rating.

\section{Round 3}

In Round 3, panel members received a de-identified summary of the Round 2 competency ratings and explanations and were asked to re-rate each competency using the same criteria. This gave them an opportunity to change their rating after reflecting on the outcomes of Round 2.

Figure 1 provides an overview of the three-round Delphi process used in this study.

\section{Data analysis}

Data from all three Delphi rounds and the background questionnaire were downloaded from SurveyMonkey and transferred into SPSS. Percentages were generated for each rating across each competency.

\section{Compilation and use of the final list of competencies}

In the literature, $75 \%$ agreement has been frequently accepted as the minimum level to represent consensus ${ }^{18}$ and the same was adopted in this study. Given this study aimed to propose a community-AF-specific sports trainer education structure, three levels of consensus were applied. A competency was accepted as 'required' by a sports trainer to effectively perform the activities required to the standards expected at a community-AF club if $\geq 75 \%$ of the participants in Round 3 rated it as 'essential' or 'expected' - these competencies were included as mandatory in the sports trainer education structure. To err on the side of including rather than excluding a relevant competency, the threshold level of agreement for excluding a competency was set higher. A competency was accepted as 'not required' if $\geq 85 \%$ of the participants in Round 3 rated it as 'ideal' or 'not required' these competencies were excluded from the education structure. All competencies that were neither 'required' nor 'not required' were included as optional in the education structure.

\section{RESULTS}

\section{Profile of the expert panel}

Thirteen (81\%) of the 16 panel members were aged $40-59$ years and 15 (94\%) were men. The self-reported ratings of current involvement, experience, qualifications, knowledge and overall expertise in community-AF and sports trainer-related activities are summarised in table 1 . All of those who selfreported having a little/some $(n=7)$ overall expertise in sports trainer-related activities also reported having a lot/very extensive overall expertise in community-AF. The following freetext responses provide an indication of the relevant expertise of some panel members.

One panel member described his expertise in community football as: "I have committed a life time to the ... (name removed) ... Football Club and the care and treatment of its 
18 experts identified by project team and invited to participate in three-round online Delphi Two experts declined to participate

Project team reviewed suggested
changes/additions
- Two new competencies added
- Minor wording changes

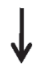

\section{Round 2}

- Revised list of 77 competencies based on Round 1 outcomes

- Panel asked to rate competencies as: Essential;

Expected: Ideal; or Not Required

- Panel encouraged to explain rating

\section{Round 1}

- Aim: a comprehensive list of competencies potentially required by community-AF sports trainers

- 74 competencies informed by evidence of injuries in community-AF, content of current sports first-aid and sports trainer education courses, and project team's expertise

- Panel asked to suggest changes, add new competencies and make general comments

- Included background information questionnaire covering demographic and selfrating of expertise in community-AF and sports-trainer activities
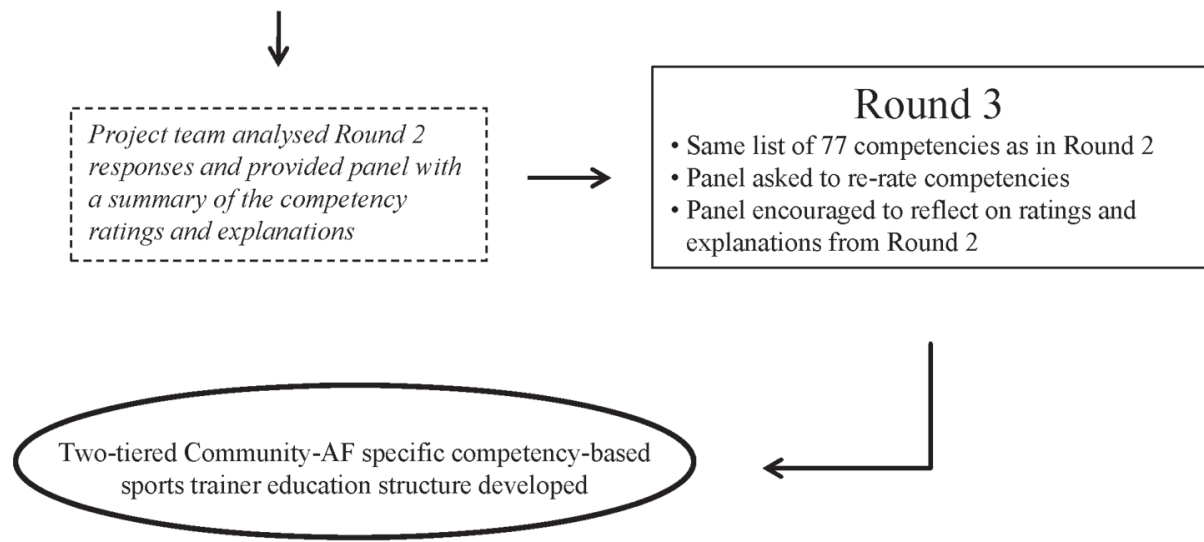

Figure 1 Overview of the Delphi process used in this study.

players and injuries at all levels of the club. The ... (name removed) . . Football Club is a 'way of life' for me and not simply a weekend past time. Apart from the core sports trainers duties, I have actively involved myself in other club activities that benefit the club." Another responded "I have been involved in community football for approximately 40 years as a player, coach and administrator".

One panel member described his expertise in sports trainerrelated activities as: "Very high, as I work with physios organising rehab programs for players. Taping players for training and game days, the standard has to be good. Have had experience with AFL teams so you have to be consistent. Have a good knowledge of how to treat and prevent injuries, how to stretch effectively before and after the game. Also conduct taping nights for other trainers throughout the ... (name of region removed) ..."

Based on Round 1, the number of competencies was increased from 74 to 77 for Rounds 2 and 3. Two new competencies were added and one existing competency was divided into two separate competencies. Some minor wording changes (eg, the word 'immediate' added in front of the term 'injury management' and adding or deleting examples) were also made to 10 competencies. Although some panel members suggested deleting some competencies from the original list, these suggestions were not acted upon because the purpose of Round 1 was to build a comprehensive list, not to reduce it.

Of the 77 competencies circulated in Round 3, there was consensus that 47 (61\%) of them were 'required' by a sports trainer at a community-AF club. There was also consensus that four $(5 \%)$ competencies were 'not required'. There was no consensus on the remaining 26 competencies.

Within the 'role and importance' category, there was consensus that three of four competencies were 'required' (table 2) compared with 8 of 10 'responsibilities' competencies (table 3); all 'emergency management procedures and responses' competencies (table 4); 22 of 26 'injury and illness assessment and management' competencies (table 5); all 'taping' competencies (table 6); 2 of 17 'injury prevention and risk management' competencies (table 7); and none of the 'health promotion' competencies (table 8). All 'not required' competencies were in the health promotion category.

The Round 2 free-text explanations suggest that, when a competency was rated as 'ideal' or 'not required', the competency was often considered beyond the scope of the sports trainers' role. For example, one panel member commented "I see the trainers' main role is managing injuries when they happen and the safety of the person injured. The role of injury prevention and risk management is the role of other people", 
Table 1 Delphi experts' self-rating of their current involvement, experience, qualifications, knowledge and overall expertise in community-AF and sports trainer-related activities compared with a member of the general public

\begin{tabular}{|c|c|c|c|c|c|c|c|c|c|c|c|c|c|c|c|c|c|c|c|c|}
\hline & \multicolumn{20}{|c|}{ Self-rating compared with that of a member of the general public } \\
\hline & \multicolumn{10}{|c|}{ Community-AF } & \multicolumn{10}{|c|}{ Sports trainer-related activities } \\
\hline & \multicolumn{2}{|c|}{$\begin{array}{l}\text { Current } \\
\text { involvement }\end{array}$} & \multicolumn{2}{|c|}{ Experience } & \multicolumn{2}{|c|}{ Qualifications } & \multicolumn{2}{|c|}{ Knowledge } & \multicolumn{2}{|c|}{$\begin{array}{l}\text { Overall } \\
\text { expertise }\end{array}$} & \multicolumn{2}{|c|}{$\begin{array}{l}\text { Current } \\
\text { involvement }\end{array}$} & \multicolumn{2}{|c|}{ Experience } & \multicolumn{2}{|c|}{ Qualifications } & \multicolumn{2}{|c|}{ Knowledge } & \multicolumn{2}{|c|}{$\begin{array}{l}\text { Overall } \\
\text { expertise }\end{array}$} \\
\hline & $\mathbf{n}$ & $\%$ & $\mathbf{n}$ & $\%$ & $\mathbf{n}$ & $\%$ & n & $\%$ & $\mathbf{n}$ & $\%$ & $\mathbf{n}$ & $\%$ & $\mathbf{n}$ & $\%$ & $\mathbf{n}$ & $\%$ & $\mathbf{n}$ & $\%$ & n & $\%$ \\
\hline None & 0 & 0 & 0 & 0 & 0 & 0 & 0 & 0 & 0 & 0 & 1 & 6 & 0 & 0 & 2 & 12 & 0 & 0 & 0 & 0 \\
\hline A little & 0 & 0 & 0 & 0 & 0 & 0 & 0 & 0 & 0 & 0 & 3 & 19 & 3 & 19 & 3 & 19 & 0 & 0 & 2 & 12 \\
\hline Some & 1 & 6 & 0 & 0 & 1 & 6 & 1 & 6 & 1 & 6 & 3 & 19 & 3 & 19 & 2 & 12 & 6 & 37 & 5 & 31 \\
\hline A lot & 4 & 25 & 5 & 31 & 8 & 50 & 8 & 50 & 8 & 50 & 2 & 12 & 2 & 12 & 2 & 12 & 3 & 19 & 3 & 19 \\
\hline Very extensive & 11 & 69 & 11 & 69 & 7 & 44 & 7 & 44 & 7 & 44 & 7 & 44 & 8 & 50 & 7 & 44 & 7 & 44 & 6 & 37 \\
\hline
\end{tabular}

AF, Australian Football.

whereas another succinctly reported "Health promotion is not our job." Some competencies that some panel members rated as 'ideal' or 'not required' were considered the responsibility of others such as the governing association, club administrators or coaches: "Many of these areas will be covered by others within the club, from team managers, coaches to fitness coaches depending on the setup of the club. It is unrealistic and rare to have a sports trainer looking after all of these areas" and "In some places, all games are played on the same ovals so the association does ground checks for safety."

\section{Proposed community-AF-specific sports trainer education structure}

Based on the results of Round 3, figure 2 illustrates a proposed two-tiered community-AF-specific sports trainer education structure. The first tier (Sports Trainer) consists of six mandatory modules (The Role of the Sports Trainer 1; The Responsibilities of the Sports Trainer; Emergency Management; Injury and Illness Assessment and Immediate Management 1; Taping; and Injury Prevention and Risk Management 1) and includes the 47 'required' competencies from this study. Sports trainers at a community-AF match or practice session would be expected to have completed all mandatory modules. The second tier consists of six optional modules (Health Promotion; Player Performance and Welfare; Playing Environment and Equipment; Injury Prevention and Risk Management 2; The Role of the Sports Trainer 2; and Injury and Illness Assessment and Immediate Management 2). Community-AF sports trainers would be encouraged to complete
Table 2 Delphi Round 3 responses to sports trainers' competencies related to role and importance $(n=16)$

\begin{tabular}{llllll}
\hline $\begin{array}{l}\text { Competency number } \\
\text { and name }\end{array}$ & $\begin{array}{l}\text { Consensus } \\
(\%)\end{array}$ & $\begin{array}{l}\text { Essential } \\
\text { (n) }\end{array}$ & $\begin{array}{l}\text { Expected } \\
\text { (n) }\end{array}$ & $\begin{array}{l}\text { Ideal } \\
\text { (n) }\end{array}$ & $\begin{array}{l}\text { Not required } \\
\text { (n) }\end{array}$
\end{tabular}

A sports trainer involved with a community-AF club should understand the role and importance of

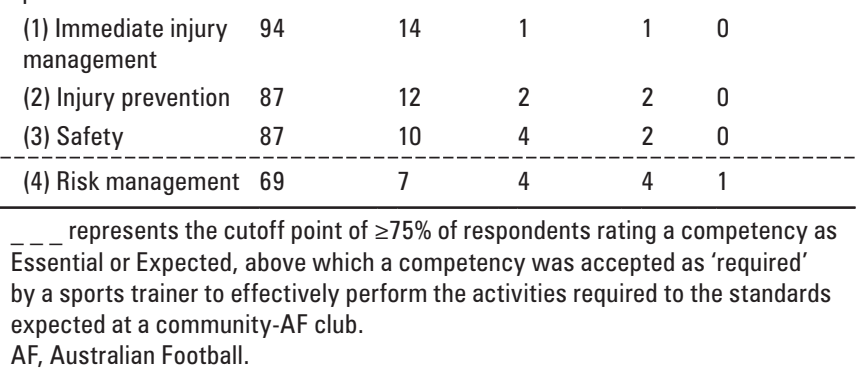

these optional modules. The specific competencies included in each module are shown in figure 2 using competency numbers cross-referenced to tables $2-8$.

\section{DISCUSSION}

Although the original list of competencies circulated in Round 1 was comprehensive, the real value of the Delphi process was in Round 3. Through the consensus process, the responses of panel members were able to be used to categorise the original 77 competencies into: 47 'required' competencies, 26 'optional' competencies and four 'not required' competencies.

Table 3 Delphi Round 3 responses to sports trainers' competencies related to responsibilities $(n=16)$

\begin{tabular}{|c|c|c|c|c|c|}
\hline Competency number and name & Consensus (\%) & Essential (n) & Expected (n) & Ideal (n) & Not required (n) \\
\hline \multicolumn{6}{|c|}{ A sports trainer involved with a community-AF club should understand the responsibilities of a sports trainer in the context of $\mathrm{AF}$ including } \\
\hline (5) Referrals to healthcare professional & 94 & 9 & 6 & 1 & 0 \\
\hline (6) First-aid equipment & 94 & 13 & 2 & 1 & 0 \\
\hline (7) First-aid facilities & 87 & 8 & 6 & 2 & 0 \\
\hline (8) Legal responsibilities & 87 & 6 & 8 & 2 & 0 \\
\hline (9) Injury management & 87 & 12 & 2 & 2 & 0 \\
\hline (10) Injury prevention & 87 & 12 & 2 & 2 & 0 \\
\hline (11) Record keeping & 87 & 5 & 9 & 2 & 0 \\
\hline $\begin{array}{l}\text { (12) Relationships and communication with players, } \\
\text { coaches, administrators, umpires and healthcare } \\
\text { professionals }\end{array}$ & 81 & 6 & 7 & 3 & 0 \\
\hline (13) Preparticipation medical history and information & 68 & 6 & 5 & 5 & 0 \\
\hline (14) Health promotion & 56 & 0 & 9 & 3 & 4 \\
\hline
\end{tabular}

____ represents the cutoff point of $\geq 75 \%$ of respondents rating a competency as Essential or Expected, above which a competency was accepted as 'required' by a sports trainer to effectively perform the activities required to the standards expected at a community-AF club.

$\mathrm{AF}$, Australian Football. 
Table 4 Delphi survey 3 responses to sports trainers' competencies related to emergency management procedures and responses ( $\mathrm{n}=16$ )

\begin{tabular}{|c|c|c|c|c|c|}
\hline Competency number and name & Consensus $(\%)$ & Essential (n) & Expected (n) & Ideal (n) & Not required (n) \\
\hline \multicolumn{6}{|c|}{ A sports trainer involved with a community Australian Football club should be competent in Emergency Management Procedures and Responses including } \\
\hline (15) Calling an ambulance & 100 & 12 & 4 & 0 & 0 \\
\hline $\begin{array}{l}\text { (17) On-field communication - signals, team work, } \\
\text { umpires }\end{array}$ & 94 & 12 & 3 & 1 & 0 \\
\hline $\begin{array}{l}\text { (18) Understanding priorities - danger, response, airway, } \\
\text { breathing, circulation }\end{array}$ & 94 & 15 & 0 & 1 & 0 \\
\hline $\begin{array}{l}\text { (20) Emergency planning - access to telephone, venue } \\
\text { access for emergency vehicles, first-aid equipment, etc }\end{array}$ & 84 & 11 & 4 & 1 & 0 \\
\hline
\end{tabular}

Table 5 Delphi survey 3 responses to sports trainers' competencies related to injury and illness assessment and immediate management ( $\mathrm{n}=16$ )

\begin{tabular}{|c|c|c|c|c|c|}
\hline Competency number and name & Consensus (\%) & Essential (n) & Expected (n) & Ideal (n) & Not required $(\mathrm{n})$ \\
\hline \multicolumn{6}{|c|}{ A sports trainer involved with a community-AF club should be competent in Injury and Illness Assessment and Immediate Management in relation to } \\
\hline (21) Spinal/neck injuries & 94 & 12 & 3 & 1 & 0 \\
\hline (22) Concussion and brain injuries & 94 & 12 & 3 & 1 & 0 \\
\hline (23) Unconscious casualties & 94 & 13 & 2 & 1 & 0 \\
\hline (24) Dislocations & 94 & 12 & 3 & 1 & 0 \\
\hline (25) Teeth and jaw injuries & 94 & 9 & 6 & 1 & 0 \\
\hline (28) Bleeding & 94 & 14 & 1 & 1 & 0 \\
\hline (29) Fractures & 94 & 13 & 2 & 1 & 0 \\
\hline (30) Dehydration & 87 & 7 & 7 & 2 & 0 \\
\hline (31) Shock & 87 & 6 & 8 & 2 & 0 \\
\hline (32) Lower limb injuries - knees, ankles, feet, hamstring and Achilles & 87 & 10 & 4 & 2 & 0 \\
\hline (33) Shoulder injuries & 87 & 10 & 4 & 2 & 0 \\
\hline $\begin{array}{l}\text { (38) Airway/respiratory distress (including choking, airway obstruction } \\
\text { and asthma) }\end{array}$ & 87 & 13 & 1 & 2 & 0 \\
\hline (39) Cardiopulmonary resuscitation (including defibrillation) & 81 & 11 & 2 & 3 & 0 \\
\hline (40) Ear injuries & 75 & 5 & 7 & 4 & 0 \\
\hline (41) Severe allergic reactions - anaphylaxis & 75 & 7 & 5 & 4 & 0 \\
\hline (42) Infection control - communicable diseases & 75 & 2 & 10 & 3 & 1 \\
\hline (43) Extremes of temperature & 69 & 3 & 8 & 4 & 1 \\
\hline $\begin{array}{l}\text { (44) Trunk injuries - internal organs, genitals, ribs, chest, thorax and } \\
\text { back }\end{array}$ & 69 & 5 & 6 & 5 & 0 \\
\hline (45) Overuse and chronic injuries & 62 & 1 & 9 & 6 & 0 \\
\hline
\end{tabular}

represents the cutoff point of $\geq 75 \%$ of respondents rating a competency as Essential or Expected, above which a competency was accepted as 'required' by a sports trainer to effectively perform the activities required to the standards expected at a community-AF club.

AF, Australian Football.

The competencies that were categorised as 'required' by sports trainers to effectively perform the activities to the standards expected at community-AF clubs could, for the purposes of education and accreditation, justifiably be considered mandatory. These competencies tended to be related to: understanding the role and responsibilities of a sports trainer in a community-AF club; assessing, responding to and appropriately managing community-AF-related emergencies; and assessing and managing common (lower limb injuries, open wounds injuries, soft tissue injuries) and uncommon but serious (an unconscious casualty, airway or respiratory distress) community-AF-related injuries. This is consistent with a risk assessment/management approach where the high-frequency (or likelihood), low or medium consequence injuries and low-frequency, severe consequence injuries are given highest priority. ${ }^{19}$

The fact that no consensus was reached on 26 competencies is also important and suggests that the panel considered it desirable but not necessary for community-AF sports trainers to have these competencies, and they could therefore legitimately be considered 'optional' in any education structure. These competencies tended to be those more related to: assessing and managing non-community-AF-related injuries that happen infrequently in a community-AF setting (eg, burns 
Table 6 Delphi survey 3 responses about sports trainers' competencies related to taping $(n=16)$

\begin{tabular}{|c|c|c|c|c|c|}
\hline Competency number and name & Consensus (\%) & Essential (n) & Expected (n) & Ideal (n) & Not required (n) \\
\hline \multicolumn{6}{|c|}{ A sports trainer involved with a community Australian Football club should be competent in taping } \\
\hline (47) Ankles & 93 & 13 & 2 & 1 & 0 \\
\hline (48) Thumbs & 93 & 13 & 2 & 1 & 0 \\
\hline (49) Fingers & 93 & 13 & 2 & 1 & 0 \\
\hline (50) Shoulders & 75 & 11 & 1 & 4 & 0 \\
\hline (51) Knees & 75 & 11 & 1 & 4 & 0 \\
\hline
\end{tabular}

Table 7 Delphi survey responses to sports trainers' competencies related to injury prevention and risk management $(n=15)$

\begin{tabular}{|c|c|c|c|c|c|}
\hline Competency number and name & Consensus (\%) & Essential (n) & Expected (n) & Ideal (n) & Not required (n) \\
\hline \multicolumn{6}{|c|}{ A sports trainer involved with a community-AF club should be competent and knowledgeable in Injury Prevention and Risk Management including } \\
\hline (53) Return to play & 86 & 8 & 5 & 2 & 0 \\
\hline (54) Massage & 80 & 6 & 6 & 3 & 0 \\
\hline (55) Fluid replacement & 73 & 6 & 5 & 3 & 1 \\
\hline (56) Protective equipment & 60 & 2 & 7 & 6 & 0 \\
\hline (57) Stretching & 60 & 2 & 7 & 6 & 1 \\
\hline (60) Recovery & 47 & 2 & 5 & 6 & 2 \\
\hline $\begin{array}{l}\text { (61) Working with specific population groups - children, mature ath- } \\
\text { letes, adolescents, athletes with a disability and female athletes }\end{array}$ & 40 & 3 & 3 & 8 & 1 \\
\hline (62) Drugs in sport & 40 & 2 & 4 & 6 & 3 \\
\hline (63) Playing environment - playing surface and goal posts & 33 & 1 & 4 & 6 & 4 \\
\hline (64) Nutrition & 33 & 0 & 5 & 6 & 4 \\
\hline (68) Strength and conditioning & 27 & 0 & 4 & 7 & 4 \\
\hline $\begin{array}{l}\text { (69) Contraindications of participation with infectious diseases and } \\
\text { medical conditions }\end{array}$ & 27 & 2 & 2 & 10 & 1 \\
\hline (70) Modified sports equipment & 20 & 0 & 3 & 9 & 3 \\
\hline
\end{tabular}

__ _ represents the cutoff point of $\geq 75 \%$ of respondents rating a competency as Essential or Expected, above which a competency was accepted as 'required' by a sports trainer to effectively perform the activities required to the standards expected at a community-AF club.

AF, Australian Football.

Table 8 Delphi survey 3 responses to sports trainers' competencies related to health promotion $(n=15)$

\begin{tabular}{|c|c|c|c|c|c|}
\hline $\begin{array}{l}\text { Competency number } \\
\text { and name }\end{array}$ & $\begin{array}{l}\text { Consensus } \\
(\%)\end{array}$ & Essential & Expected & Ideal & $\begin{array}{l}\text { Not } \\
\text { required }\end{array}$ \\
\hline
\end{tabular}

A sports trainer involved with a community-AF club should be competent and knowledgeable in

\begin{tabular}{llllll} 
(71) Alcohol & 47 & 3 & 4 & 4 & 4 \\
(72) Sports psychology & 27 & 0 & 4 & 7 & 4 \\
(73) Burns & 27 & 1 & 3 & 7 & 4 \\
\hline (74) Fair play & 13 & 1 & 1 & 6 & 7 \\
(75) Skill development & 7 & 0 & 1 & 5 & 9 \\
(76) Drowning & 7 & 0 & 1 & 7 & 7 \\
(77) Equity in & 7 & 0 & 1 & 4 & 10 \\
\multicolumn{1}{c}{ participation } & & & & & \\
\hline
\end{tabular}

_ represents the cutoff point of $\geq 75 \%$ of respondents rating a competency as Essential or Expected, above which a competency was accepted as 'required' by a sports trainer to effectively perform the activities required to the standards expected at a community-AF club.

represents the cutoff point of $\geq 85 \%$ of respondents rating a competency as $\overline{\text { Ideal }}$ or Not Required, below which a competency was accepted as 'not required' by a sports trainer to effectively perform the activities required to the standards expected at a community-AF club.

$\mathrm{AF}$, Australian Football. and stings; extremes of temperature); injury prevention (eg, preparticipation medical history and information; protective equipment and playing environment); player performance (eg, warm up and cool down; strength and conditioning); and the promotion of positive health (eg, nutrition; drugs; alcohol). The two community-AF-specific competencies in the Injury and Illness Assessment and Immediate Management category that were not considered 'required' may have been rated this way because trunk injuries are relatively uncommon in community-AF and overuse/chronic injuries are generally slow onset and less relevant to first-aid.

The panel members also agreed that four competencies (related to competence in drowning, fair play, skill development and equity in participation) were 'not required' and therefore could justifiably be removed from any education structure. It is likely that these competencies were rated this way because it is almost inconceivable that they would happen in a community-AF setting (in the case of drowning) or they are clearly the responsibility of others (coaches, umpires, administrators, etc.).

There has been considerable interest in using community sport to promote health..$^{20-22}$ Although it has not been suggested that sports trainers/first-aid providers should be 

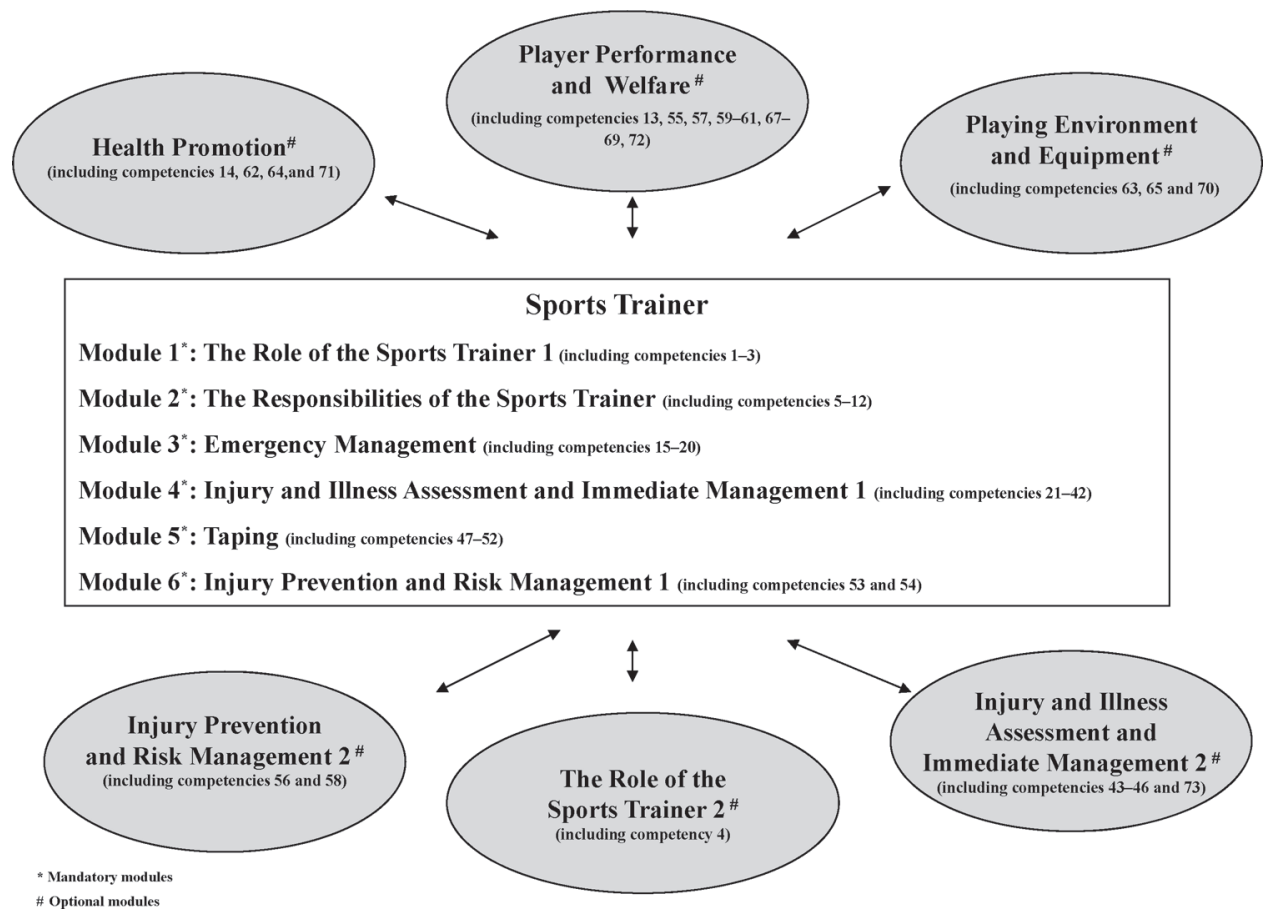

Figure 2 Proposed community Australian Football-specific sports trainer education course.

responsible for health promotion-related activities, because there are limited numbers of volunteers in community sporting organisations, sports trainers could be targeted to take on this role. Panel members in this study did not believe that the sports trainer role should include health promotion-related activities. Those advocating for health promoting community sports clubs will need to either negotiate with sports trainers to undertake this role or identify others to fulfil this role.

The most important outcome of this study is that community-AF sports trainer educators can now match their course content to the competencies that sports trainers need. This should minimise the risk of the education being irrelevant and potentially too expensive or time consuming. The study findings should also be used to ensure that any AFL first-aidrelated policies for community-AF do not place unnecessary demands on sports trainers that will make them unwilling to take on the role.

It can be a challenge to recruit and retain expert panel participants using the Delphi method ${ }^{14}$ because of the continued commitment required from participants who are repeatedly questioned about the same topic, using a slightly modified questionnaire. Although the iterative nature of the Delphi method allows panel members to reflect on and alter their responses on the basis of anonymous feedback from others, ${ }^{23}$ it can also lead to substantial attrition among panellists between the start and the end of the process. ${ }^{18}$ One of the strengths of this study was the high level of initial engagement (89\% of invited experts participated) and retention (100\%) of experts. We can only speculate that the research topic; endorsement and active support of the sport's governing body; convenience of the online survey process; quick processing, summarising and recirculating of early-round survey data; and the engagement of end users in the early stages of policy research, all contributed to motivating the experts to engage and continue with participation in this study. A second major strength was the high level of relevant background possessed by the 16 panel members with over $50 \%$ self-reporting 'a lot' or 'very extensive' to all 10 categories included in the background questionnaire.

A number of limitations of this study need to be acknowledged. First, it may have been difficult for panel members to interpret the meaning of and distinguish between some overlapping competencies (eg, safety, risk management and injury prevention in the Role and Importance category). Second, the list of competencies included both 'knowledge' (eg, understanding the role of a sports trainer) and 'skill' (eg, being able to perform cardiopulmonary resuscitation) based competencies and panel members might have had difficulty comparing and rating these different types of competencies. Third, some competencies were more abstract in nature (eg, 'health promotion' and 'equity in participation') and panel members might not have understood these as well as they understood other, more specific and objective competencies (eg, 'ankle' taping and immediate management of 'bleeding'). In addition, the standard required for a sports trainer to be considered competent was not considered in this study, and it is possible that different panel members may have interpreted this differently. Finally, the definition of community-AF used in this study was broad and included well-resourced state-league and large metropolitan clubs alongside less well-resourced smaller rural clubs, and clubs with senior players alongside clubs with junior players. Previous research suggests that it is difficult to develop standards (or in this case competencies) that are relevant and applicable across all types of community sporting organisations and all levels of competition. ${ }^{20}$

\section{CONCLUSION}

The competencies considered required by community-AF sports trainers include those related to understanding their roles and responsibilities, recognising and appropriately managing emergencies, assessing and immediately managing community-AFspecific common and potentially serious injuries and taping commonly injured joints. The expert consensus is that it is 


\section{What is already known on this topic}

- Providing first-aid is a fundamental risk management strategy for most sports.

- Generic sports first-aid and sports trainer education courses are available, but these are not generally tailored to the needs of specific sports.

\section{What this study adds}

- To meet the context-specific requirements, community Australian Football (community-AF) sports trainer education should focus on ensuring that participants are competent in recognising and appropriately managing emergencies, assessing and immediately managing community-AFspecific common and potentially serious injuries and taping commonly injured joints.

- To avoid overburdening participants, optional community-AF sports trainer education should focus on: health promotion; player performance and welfare; playing environment and equipment; injury prevention and risk management; and the assessment and immediate management of common nonAF-related injuries and illnesses.

- The Delphi method is a useful and manageable research process for gaining expert consensus among community sport administrators and service providers.

desirable rather than necessary for community-AF sports trainers to be competent in risk management, injury prevention, health promotion and the assessment and immediate management of non-community-AF-related injuries and illnesses.

Contributors Both authors contributed to the conception and design of the study, the analysis and interpretation of the data, drafting the article and revising it critically for important intellectual content. Both authors provided final approval of the version to be published.

Acknowledgements The project was conducted through an active collaboration between the AFL and the researchers. The AFL members of the project team were as follows: Mr Lawrie Woodman (Manager Coaching, Umpiring and Volunteers), Mr Peter Romaniw (Community Development Coordinator), Dr Hugh Seward (AFL Medical Officers Association) and Mr Nick Ames (Consultant physiotherapist to AFL Junior Development Program). The study was conducted when the two authors were employed at the University of Ballarat, and the paper write-up occurred when they were employed at Monash University. The project would not have been possible without the dedication and commitment of the experts who participated in the Delphi process.

Funding This project was funded by a grant from the Australian Football League (AFL) Research Board. CFF was supported by an NHMRC Principal Research
Fellowship (ID: 565900). AD was funded by the AFL grant during the conduct phase and an NHMRC Project Grant (ID: 565907) during the write-up phase.

\section{Competing interests None.}

Ethics approval The study was approved by the University of Ballarat Human Research Ethics Committee.

Provenance and peer review Not commissioned; externally peer reviewed.

\section{REFERENCES}

1. McManus A, Stevenson M, Finch CF, et al. Incidence and risk factors for injury in non-elite Australian Football. J Sci Med Sport 2004;7:384-91.

2. Braham R, Finch CF, McIntosh A, et al. Community level Australian Football: a profile of injuries. J Sci Med Sport 2004;7:96-105.

3. Gabbe B, Finch C, Wajswelner $\mathrm{H}$, et al. Australian football: injury profile at the community level. J Sci Med Sport 2002;5:149-60.

4. Gabbe BJ, Finch CF. Injury countermeasures in Australian Football. J Sci Med Sport 2000;3(2 Supp 1):31-40.

5. Finch CF, McGrath A. SportSafe Australia: A National Sports Safety Framework. A report prepared for the Australian Sports Injury Prevention Taskforce. Canberra, ACT: Australian Sports Commission, 1997:56-7.

6. Zazryn T, Finch C, Garnham A. Is safety a priority for football clubs? Sport Health 2004;21:19-24.

7. Casey M, Finch CF, Mahoney M, et al. Sport safety policies and practices in two rural Victorian communities. J Sci Med Sport 2004;7:226-31.

8. Donaldson A, Forero R, Finch CF. The first aid policies and practices of community sports clubs in northern Sydney, Australia. Health Promot J Austr 2004;15:156-62.

9. Finch CF, Hennessy M. The safety practices of sporting clubs/centres in the city of Hume. J Sci Med Sport 2000;3:9-16.

10. Donaldson A, Forero R, Finch CF, et al. A comparison of the sports safety policies and practices of community sports clubs during training and competition in northern Sydney, Australia. Br J Sports Med 2004;38:60-3.

11. Cunningham $\mathbf{A}$. An audit of first aid qualifications and knowledge among team officials in two English youth football leagues: a preliminary study. Br J Sports Med 2002;36:295-300.

12. Abernethy L, MacAuley D, McNally 0 , et al. Immediate care of school sport injury. Inj Prev 2003;9:270-3.

13. Vangsness CT Jr, Hunt T, Uram M, et al. Survey of health care coverage of high school football in southern California. Am J Sports Med 1994;22:719-22.

14. Hasson F, Keeney S, McKenna H. Research guidelines for the Delphi survey technique. J Adv Nurs 2000;32:1008-15.

15. Katcher ML, Meister AN, Sorkness CA, et al. Use of the modified Delphi technique to identify and rate home injury hazard risks and prevention methods for young children. Inj Prev 2006;12:189-94.

16. Kennedy HP. Enhancing Delphi research: methods and results. J Adv Nurs 2004:45:504-11.

17. Williams PL, Webb C. The Delphi technique: a methodological discussion. J Adv Nurs 1994;19:180-6.

18. Keeney S, Hasson F, McKenna H. Consulting the oracle: ten lessons from using the Delphi technique in nursing research. J Adv Nurs 2006;53:205-12.

19. Fuller CW, Ward CJ. An empirical approach for defining acceptable levels of risk: a case study in team sports. Inj Prev 2008;14:256-61.

20. Kokko S, Kannas L, Villberg J. Health promotion profile of youth sports clubs in Finland: club officials' and coaches' perceptions. Health Promot Int 2009;24:26-35.

21. Eime RM, Payne WR, Harvey JT. Making sporting clubs healthy and welcoming environments: a strategy to increase participation. J Sci Med Sport 2008; 11:146-54

22. Kelly B, Baur LA, Bauman AE, et al. Health promotion in sport: an analysis of peak sporting organisations' health policies. J Sci Med Sport 2010;13:566-7.

23. Crisp J, Pelletier D, Duffield C, et al. The Delphi method? Nurs Res 1997;46:116-18. 


\title{
Identifying context-specific competencies required by community Australian Football sports trainers
}

\author{
Alex Donaldson, Caroline F Finch
}

Australian Centre for Research into Injury in Sport and its Prevention (ACRISP), Monash Injury Research Institute (MIRI), Monash University, Clayton, Victoria, Australia

\section{Correspondence to}

Dr Alex Donaldson, Room 315,

Building 70, Clayton Campus, Monash University, Clayton,

VIC 3800, Australia;

alex.donaldson@monash.edu

Accepted 30 August 2011

Published Online First

6 October 2011

\section{ABSTRACT}

Background First-aid is a recommended injury prevention and risk management strategy in community sport; however, little is known about the sport-specific competencies required by first-aid providers.

Objective To achieve expert consensus on the competencies required by community Australian Football (community-AF) sports trainers.

Study design A three-round online Delphi process.

Setting Community-AF.

Participants 16 Australian sports first-aid and community-AF experts.

Outcome measures Rating of competencies as either 'essential', 'expected', 'ideal' or 'not required'.

Results After Round 3, 47 of the 77 (61\%) competencies were endorsed as 'essential' or 'expected' for a sports trainer to effectively perform the activities required to the standards expected at a community-AF club by $\geq 75 \%$ of experts. These competencies covered: the role of the sports trainer; the responsibilities of the sports trainer; emergency management; injury and illness assessment and immediate management; taping; and injury prevention and risk management. Four competencies (5\%) were endorsed as 'ideal' or 'not required' by $\geq 85 \%$ of experts and were excluded from further consideration. The 26 competencies where consensus was not reached were retained as secondtier, optional competencies.

Conclusions Sports trainers are important members of on-field first-aid teams, providing support to both injured players and other sports medicine professionals. The competencies identified in this study provide the basis of a proposed two-tiered community-AF-specific sports trainer education structure that can be implemented by the peak sports body. This includes six mandatory modules, relating to the 'required' competencies, and a further six optional modules covering competencies on which consensus was not reached.

\section{INTRODUCTION}

It is now widely accepted that injuries, including serious ones, can occur during participation in community Australian Football (community$\mathrm{AF})^{1-3}$ and that injury prevention strategies, including the provision of appropriate first-aid, should be adopted. ${ }^{4}{ }^{5}$ Previous studies have described the first-aid policies and associated practices of community-AF clubs ${ }^{6}$ and other Australian community sports clubs. ${ }^{8-10}$ Internationally, the qualifications, experience or knowledge of firstaid providers have been described across a range of sports and settings. ${ }^{11-13}$

First-aid providers are an important component of on-field injury management teams, providing support to both injured players and other sports medicine professionals. However, to our knowledge, no studies have been published in the peer-reviewed literature reporting the specific competencies - defined as the knowledge, skills and attitudes needed to effectively perform the activities required to the standards expected required for first-aid providers in any community sport setting.

The Australian Football League (AFL), the national governing body for AF, considers sports trainers (ie, first-aid providers) part of the fabric of every club and that they play a key role in player preparation and safety at all levels. However, community-AF clubs, like their counterparts in other sports, have experienced considerable difficulty in recruiting and retaining suitably competent sports trainers. ${ }^{67}$ The AFL believes that the lack of community-AFspecific relevance of the currently available sports trainer education courses is a key factor contributing to this difficulty. As a consequence, the AFL also believes that potential community-AF sports trainers are reluctant to attend currently available education courses because they are perceived as time consuming, costly, including/focusing too much on some irrelevant content and not including/focusing enough on some relevant content. This article identifies the competencies that experts agree are required by community-AF sports trainers and proposes a community-AF-specific competency-based sports trainer education structure.

\section{METHODS}

A Delphi technique ${ }^{14}$ was used to reach consensus among a panel of experts without engaging them in direct discussions. ${ }^{15}$ The Delphi technique is an anonymous process where experts communicate their opinions and knowledge, see how their evaluation of the issue aligns with others and reconsider and change their opinions, if desired, after viewing the findings of the group's deliberations. ${ }^{16}$ One advantage of the Delphi technique over other forms of consensus building (eg, committee meetings or focus group discussions) is that participants cannot be intimidated or inhibited from expressing their views by the presence of stronger or more hierarchically senior individuals who can dominate direct discussions. ${ }^{17}$ The major disadvantage of the indirect Delphi communication process is that participants cannot question or request further information or clarification from each other.

The University of Ballarat Human Research Ethics Committee approved the study protocol, which adhered to the fundamental Delphi 
principles of providing feedback to participants between rounds while maintaining the anonymity of participants.

\section{Expert panel formation}

The project team (comprising both authors, two community-AF administrators, an AF-specialist sports physician and an AF-specialist physiotherapist) identified a panel of 18 people from across Australia whom they believed had sufficient current involvement, experience, qualifications and knowledge in community-AF and sports trainer-related activities to be considered 'experts'. These experts were initially informed about the study through an email from an AFL representative and recruited through a subsequent email invitation from a member of the research team.

The 16 experts who agreed to participate in the study included seven community football administrators; six sports trainers or medical officers in community-AF; two sports trainer educators; and one parent/coach. To confirm their expertise, the 16 panel members completed an online background questionnaire including items about their age and gender and 10 five-point scales (none, a little, some, a lot, very extensive) to self-rate their current involvement, experience, qualifications, knowledge and overall expertise in community-AF and sports trainer-related activities.

\section{Questionnaire development and administration}

For all three Delphi rounds, questionnaires were developed using SurveyMonkey software (http://www.surveymonkey. com), and panel members were emailed the hyperlink to the online questionnaire. Panel members were given up to 14 days to complete each questionnaire, and non-responders were sent up to two email reminders. There was a break of approximately 2 weeks between each round, and the whole process was conducted between August and October 2009.

\section{Round 1}

Round 1 of the Delphi was used to identify all the competencies that community-AF sports trainers should have in an 'ideal world'. An initial list of 74 competencies - organised into seven categories: role and importance (4 competencies); responsibilities (10); emergency management procedures and responses (5); injury and illness assessment and management (26); taping (5); injury prevention and risk management (16); and health promotion (8) - was developed based on: (1) a review of the nature and site of injuries to community-AF players; (2) current content of the Sports Medicine Australia and the Australian Rugby League sports first-aid/sports trainer education courses; and (3) the project team's expertise. Panel members were asked to: decide if, and how, each competency should be changed; comment generally on each competency; and suggest additional competencies. They were informed that their comments would be shared anonymously, through a summary report of the results of Round 1, with the panel during Round 2. The information gathered in Round 1 was collated and reviewed, and suggested changes/additions were included, if agreed as relevant by the members of the project team, in a revised list for Round 2.

\section{Round 2}

In Round 2, a revised list of 77 competencies within the same categories was circulated to the panel members who were asked to rate each competency as either:

- ESSENTIAL - all qualified sports trainers must have this competency and no community-AF practice/training or match can go ahead unless someone with this competency is present.

- EXPECTED - all qualified sports trainers should have this competency.

- IDEAL - in an ideal world where money, time and other resources are unlimited, it would be good if a qualified sports trainer had this competency.

- NOT REQUIRED - if a sports trainer had this competency it would be of no value or use to the individual trainer or to the club/players they provide services to.

Panel members were encouraged to explain why they had given a competency a particular rating.

\section{Round 3}

In Round 3, panel members received a de-identified summary of the Round 2 competency ratings and explanations and were asked to re-rate each competency using the same criteria. This gave them an opportunity to change their rating after reflecting on the outcomes of Round 2.

Figure 1 provides an overview of the three-round Delphi process used in this study.

\section{Data analysis}

Data from all three Delphi rounds and the background questionnaire were downloaded from SurveyMonkey and transferred into SPSS. Percentages were generated for each rating across each competency.

\section{Compilation and use of the final list of competencies}

In the literature, $75 \%$ agreement has been frequently accepted as the minimum level to represent consensus ${ }^{18}$ and the same was adopted in this study. Given this study aimed to propose a community-AF-specific sports trainer education structure, three levels of consensus were applied. A competency was accepted as 'required' by a sports trainer to effectively perform the activities required to the standards expected at a community-AF club if $\geq 75 \%$ of the participants in Round 3 rated it as 'essential' or 'expected' - these competencies were included as mandatory in the sports trainer education structure. To err on the side of including rather than excluding a relevant competency, the threshold level of agreement for excluding a competency was set higher. A competency was accepted as 'not required' if $\geq 85 \%$ of the participants in Round 3 rated it as 'ideal' or 'not required' these competencies were excluded from the education structure. All competencies that were neither 'required' nor 'not required' were included as optional in the education structure.

\section{RESULTS}

\section{Profile of the expert panel}

Thirteen (81\%) of the 16 panel members were aged $40-59$ years and 15 (94\%) were men. The self-reported ratings of current involvement, experience, qualifications, knowledge and overall expertise in community-AF and sports trainer-related activities are summarised in table 1 . All of those who selfreported having a little/some $(n=7)$ overall expertise in sports trainer-related activities also reported having a lot/very extensive overall expertise in community-AF. The following freetext responses provide an indication of the relevant expertise of some panel members.

One panel member described his expertise in community football as: "I have committed a life time to the ... (name removed) ... Football Club and the care and treatment of its 
18 experts identified by project team and invited to participate in three-round online Delphi Two experts declined to participate

Project team reviewed suggested
changes/additions
- Two new competencies added
- Minor wording changes

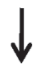

\section{Round 2}

- Revised list of 77 competencies based on Round 1 outcomes

- Panel asked to rate competencies as: Essential;

Expected: Ideal; or Not Required

- Panel encouraged to explain rating

\section{Round 1}

- Aim: a comprehensive list of competencies potentially required by community-AF sports trainers

- 74 competencies informed by evidence of injuries in community-AF, content of current sports first-aid and sports trainer education courses, and project team's expertise

- Panel asked to suggest changes, add new competencies and make general comments

- Included background information questionnaire covering demographic and selfrating of expertise in community-AF and sports-trainer activities
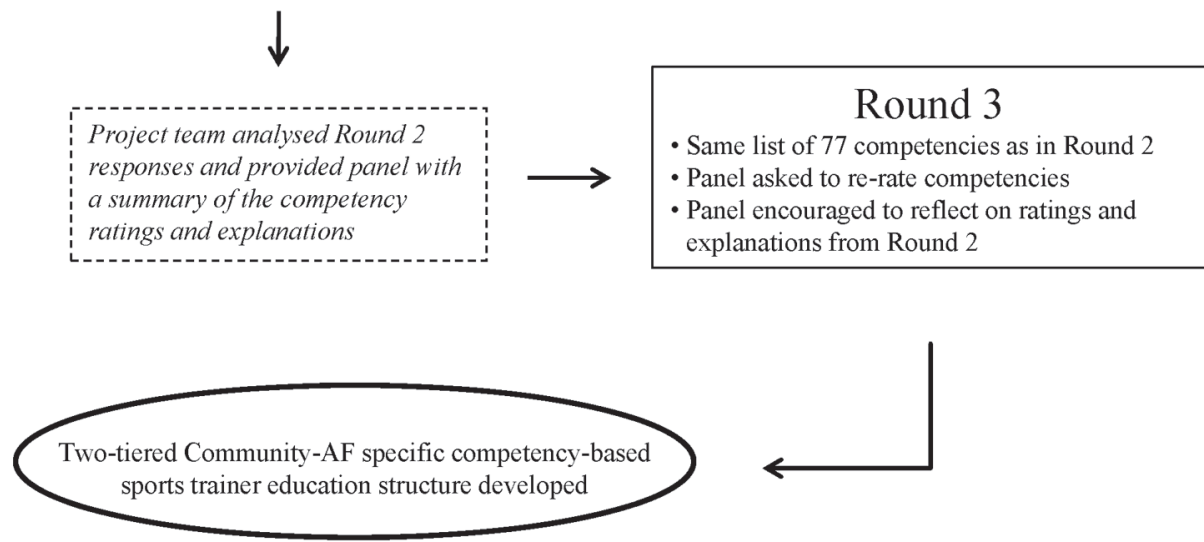

Figure 1 Overview of the Delphi process used in this study.

players and injuries at all levels of the club. The ... (name removed) . . Football Club is a 'way of life' for me and not simply a weekend past time. Apart from the core sports trainers duties, I have actively involved myself in other club activities that benefit the club." Another responded "I have been involved in community football for approximately 40 years as a player, coach and administrator".

One panel member described his expertise in sports trainerrelated activities as: "Very high, as I work with physios organising rehab programs for players. Taping players for training and game days, the standard has to be good. Have had experience with AFL teams so you have to be consistent. Have a good knowledge of how to treat and prevent injuries, how to stretch effectively before and after the game. Also conduct taping nights for other trainers throughout the ... (name of region removed) ..."

Based on Round 1, the number of competencies was increased from 74 to 77 for Rounds 2 and 3. Two new competencies were added and one existing competency was divided into two separate competencies. Some minor wording changes (eg, the word 'immediate' added in front of the term 'injury management' and adding or deleting examples) were also made to 10 competencies. Although some panel members suggested deleting some competencies from the original list, these suggestions were not acted upon because the purpose of Round 1 was to build a comprehensive list, not to reduce it.

Of the 77 competencies circulated in Round 3, there was consensus that 47 (61\%) of them were 'required' by a sports trainer at a community-AF club. There was also consensus that four $(5 \%)$ competencies were 'not required'. There was no consensus on the remaining 26 competencies.

Within the 'role and importance' category, there was consensus that three of four competencies were 'required' (table 2) compared with 8 of 10 'responsibilities' competencies (table 3); all 'emergency management procedures and responses' competencies (table 4); 22 of 26 'injury and illness assessment and management' competencies (table 5); all 'taping' competencies (table 6); 2 of 17 'injury prevention and risk management' competencies (table 7); and none of the 'health promotion' competencies (table 8). All 'not required' competencies were in the health promotion category.

The Round 2 free-text explanations suggest that, when a competency was rated as 'ideal' or 'not required', the competency was often considered beyond the scope of the sports trainers' role. For example, one panel member commented "I see the trainers' main role is managing injuries when they happen and the safety of the person injured. The role of injury prevention and risk management is the role of other people", 
Table 1 Delphi experts' self-rating of their current involvement, experience, qualifications, knowledge and overall expertise in community-AF and sports trainer-related activities compared with a member of the general public

\begin{tabular}{|c|c|c|c|c|c|c|c|c|c|c|c|c|c|c|c|c|c|c|c|c|}
\hline & \multicolumn{20}{|c|}{ Self-rating compared with that of a member of the general public } \\
\hline & \multicolumn{10}{|c|}{ Community-AF } & \multicolumn{10}{|c|}{ Sports trainer-related activities } \\
\hline & \multicolumn{2}{|c|}{$\begin{array}{l}\text { Current } \\
\text { involvement }\end{array}$} & \multicolumn{2}{|c|}{ Experience } & \multicolumn{2}{|c|}{ Qualifications } & \multicolumn{2}{|c|}{ Knowledge } & \multicolumn{2}{|c|}{$\begin{array}{l}\text { Overall } \\
\text { expertise }\end{array}$} & \multicolumn{2}{|c|}{$\begin{array}{l}\text { Current } \\
\text { involvement }\end{array}$} & \multicolumn{2}{|c|}{ Experience } & \multicolumn{2}{|c|}{ Qualifications } & \multicolumn{2}{|c|}{ Knowledge } & \multicolumn{2}{|c|}{$\begin{array}{l}\text { Overall } \\
\text { expertise }\end{array}$} \\
\hline & $\mathbf{n}$ & $\%$ & $\mathbf{n}$ & $\%$ & $\mathbf{n}$ & $\%$ & n & $\%$ & $\mathbf{n}$ & $\%$ & $\mathbf{n}$ & $\%$ & $\mathbf{n}$ & $\%$ & $\mathbf{n}$ & $\%$ & $\mathbf{n}$ & $\%$ & n & $\%$ \\
\hline None & 0 & 0 & 0 & 0 & 0 & 0 & 0 & 0 & 0 & 0 & 1 & 6 & 0 & 0 & 2 & 12 & 0 & 0 & 0 & 0 \\
\hline A little & 0 & 0 & 0 & 0 & 0 & 0 & 0 & 0 & 0 & 0 & 3 & 19 & 3 & 19 & 3 & 19 & 0 & 0 & 2 & 12 \\
\hline Some & 1 & 6 & 0 & 0 & 1 & 6 & 1 & 6 & 1 & 6 & 3 & 19 & 3 & 19 & 2 & 12 & 6 & 37 & 5 & 31 \\
\hline A lot & 4 & 25 & 5 & 31 & 8 & 50 & 8 & 50 & 8 & 50 & 2 & 12 & 2 & 12 & 2 & 12 & 3 & 19 & 3 & 19 \\
\hline Very extensive & 11 & 69 & 11 & 69 & 7 & 44 & 7 & 44 & 7 & 44 & 7 & 44 & 8 & 50 & 7 & 44 & 7 & 44 & 6 & 37 \\
\hline
\end{tabular}

AF, Australian Football.

whereas another succinctly reported "Health promotion is not our job." Some competencies that some panel members rated as 'ideal' or 'not required' were considered the responsibility of others such as the governing association, club administrators or coaches: "Many of these areas will be covered by others within the club, from team managers, coaches to fitness coaches depending on the setup of the club. It is unrealistic and rare to have a sports trainer looking after all of these areas" and "In some places, all games are played on the same ovals so the association does ground checks for safety."

\section{Proposed community-AF-specific sports trainer education structure}

Based on the results of Round 3, figure 2 illustrates a proposed two-tiered community-AF-specific sports trainer education structure. The first tier (Sports Trainer) consists of six mandatory modules (The Role of the Sports Trainer 1; The Responsibilities of the Sports Trainer; Emergency Management; Injury and Illness Assessment and Immediate Management 1; Taping; and Injury Prevention and Risk Management 1) and includes the 47 'required' competencies from this study. Sports trainers at a community-AF match or practice session would be expected to have completed all mandatory modules. The second tier consists of six optional modules (Health Promotion; Player Performance and Welfare; Playing Environment and Equipment; Injury Prevention and Risk Management 2; The Role of the Sports Trainer 2; and Injury and Illness Assessment and Immediate Management 2). Community-AF sports trainers would be encouraged to complete
Table 2 Delphi Round 3 responses to sports trainers' competencies related to role and importance $(n=16)$

\begin{tabular}{llllll}
\hline $\begin{array}{l}\text { Competency number } \\
\text { and name }\end{array}$ & $\begin{array}{l}\text { Consensus } \\
(\%)\end{array}$ & $\begin{array}{l}\text { Essential } \\
\text { (n) }\end{array}$ & $\begin{array}{l}\text { Expected } \\
\text { (n) }\end{array}$ & $\begin{array}{l}\text { Ideal } \\
\text { (n) }\end{array}$ & $\begin{array}{l}\text { Not required } \\
\text { (n) }\end{array}$
\end{tabular}

A sports trainer involved with a community-AF club should understand the role and importance of

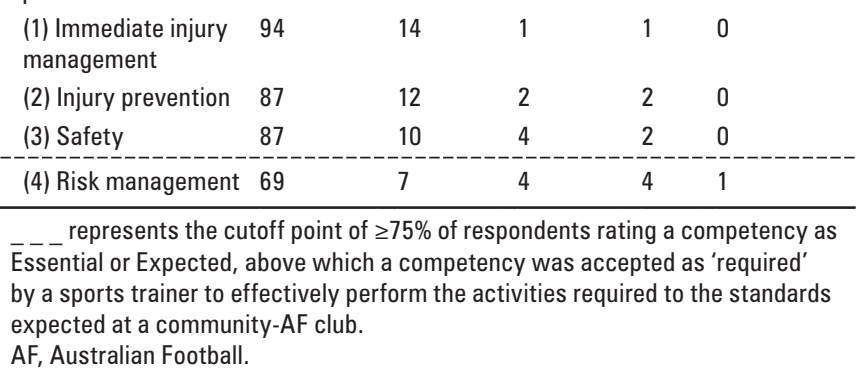

these optional modules. The specific competencies included in each module are shown in figure 2 using competency numbers cross-referenced to tables $2-8$.

\section{DISCUSSION}

Although the original list of competencies circulated in Round 1 was comprehensive, the real value of the Delphi process was in Round 3. Through the consensus process, the responses of panel members were able to be used to categorise the original 77 competencies into: 47 'required' competencies, 26 'optional' competencies and four 'not required' competencies.

Table 3 Delphi Round 3 responses to sports trainers' competencies related to responsibilities $(n=16)$

\begin{tabular}{|c|c|c|c|c|c|}
\hline Competency number and name & Consensus (\%) & Essential (n) & Expected (n) & Ideal (n) & Not required (n) \\
\hline \multicolumn{6}{|c|}{ A sports trainer involved with a community-AF club should understand the responsibilities of a sports trainer in the context of $\mathrm{AF}$ including } \\
\hline (5) Referrals to healthcare professional & 94 & 9 & 6 & 1 & 0 \\
\hline (6) First-aid equipment & 94 & 13 & 2 & 1 & 0 \\
\hline (7) First-aid facilities & 87 & 8 & 6 & 2 & 0 \\
\hline (8) Legal responsibilities & 87 & 6 & 8 & 2 & 0 \\
\hline (9) Injury management & 87 & 12 & 2 & 2 & 0 \\
\hline (10) Injury prevention & 87 & 12 & 2 & 2 & 0 \\
\hline (11) Record keeping & 87 & 5 & 9 & 2 & 0 \\
\hline $\begin{array}{l}\text { (12) Relationships and communication with players, } \\
\text { coaches, administrators, umpires and healthcare } \\
\text { professionals }\end{array}$ & 81 & 6 & 7 & 3 & 0 \\
\hline (13) Preparticipation medical history and information & 68 & 6 & 5 & 5 & 0 \\
\hline (14) Health promotion & 56 & 0 & 9 & 3 & 4 \\
\hline
\end{tabular}

____ represents the cutoff point of $\geq 75 \%$ of respondents rating a competency as Essential or Expected, above which a competency was accepted as 'required' by a sports trainer to effectively perform the activities required to the standards expected at a community-AF club.

$\mathrm{AF}$, Australian Football. 
Table 4 Delphi survey 3 responses to sports trainers' competencies related to emergency management procedures and responses ( $\mathrm{n}=16$ )

\begin{tabular}{|c|c|c|c|c|c|}
\hline Competency number and name & Consensus $(\%)$ & Essential (n) & Expected (n) & Ideal (n) & Not required (n) \\
\hline \multicolumn{6}{|c|}{ A sports trainer involved with a community Australian Football club should be competent in Emergency Management Procedures and Responses including } \\
\hline (15) Calling an ambulance & 100 & 12 & 4 & 0 & 0 \\
\hline $\begin{array}{l}\text { (17) On-field communication - signals, team work, } \\
\text { umpires }\end{array}$ & 94 & 12 & 3 & 1 & 0 \\
\hline $\begin{array}{l}\text { (18) Understanding priorities - danger, response, airway, } \\
\text { breathing, circulation }\end{array}$ & 94 & 15 & 0 & 1 & 0 \\
\hline $\begin{array}{l}\text { (20) Emergency planning - access to telephone, venue } \\
\text { access for emergency vehicles, first-aid equipment, etc }\end{array}$ & 84 & 11 & 4 & 1 & 0 \\
\hline
\end{tabular}

Table 5 Delphi survey 3 responses to sports trainers' competencies related to injury and illness assessment and immediate management ( $\mathrm{n}=16$ )

\begin{tabular}{|c|c|c|c|c|c|}
\hline Competency number and name & Consensus (\%) & Essential (n) & Expected (n) & Ideal (n) & Not required $(\mathrm{n})$ \\
\hline \multicolumn{6}{|c|}{ A sports trainer involved with a community-AF club should be competent in Injury and Illness Assessment and Immediate Management in relation to } \\
\hline (21) Spinal/neck injuries & 94 & 12 & 3 & 1 & 0 \\
\hline (22) Concussion and brain injuries & 94 & 12 & 3 & 1 & 0 \\
\hline (23) Unconscious casualties & 94 & 13 & 2 & 1 & 0 \\
\hline (24) Dislocations & 94 & 12 & 3 & 1 & 0 \\
\hline (25) Teeth and jaw injuries & 94 & 9 & 6 & 1 & 0 \\
\hline (28) Bleeding & 94 & 14 & 1 & 1 & 0 \\
\hline (29) Fractures & 94 & 13 & 2 & 1 & 0 \\
\hline (30) Dehydration & 87 & 7 & 7 & 2 & 0 \\
\hline (31) Shock & 87 & 6 & 8 & 2 & 0 \\
\hline (32) Lower limb injuries - knees, ankles, feet, hamstring and Achilles & 87 & 10 & 4 & 2 & 0 \\
\hline (33) Shoulder injuries & 87 & 10 & 4 & 2 & 0 \\
\hline $\begin{array}{l}\text { (38) Airway/respiratory distress (including choking, airway obstruction } \\
\text { and asthma) }\end{array}$ & 87 & 13 & 1 & 2 & 0 \\
\hline (39) Cardiopulmonary resuscitation (including defibrillation) & 81 & 11 & 2 & 3 & 0 \\
\hline (40) Ear injuries & 75 & 5 & 7 & 4 & 0 \\
\hline (41) Severe allergic reactions - anaphylaxis & 75 & 7 & 5 & 4 & 0 \\
\hline (42) Infection control - communicable diseases & 75 & 2 & 10 & 3 & 1 \\
\hline (43) Extremes of temperature & 69 & 3 & 8 & 4 & 1 \\
\hline $\begin{array}{l}\text { (44) Trunk injuries - internal organs, genitals, ribs, chest, thorax and } \\
\text { back }\end{array}$ & 69 & 5 & 6 & 5 & 0 \\
\hline (45) Overuse and chronic injuries & 62 & 1 & 9 & 6 & 0 \\
\hline
\end{tabular}

represents the cutoff point of $\geq 75 \%$ of respondents rating a competency as Essential or Expected, above which a competency was accepted as 'required' by a sports trainer to effectively perform the activities required to the standards expected at a community-AF club.

AF, Australian Football.

The competencies that were categorised as 'required' by sports trainers to effectively perform the activities to the standards expected at community-AF clubs could, for the purposes of education and accreditation, justifiably be considered mandatory. These competencies tended to be related to: understanding the role and responsibilities of a sports trainer in a community-AF club; assessing, responding to and appropriately managing community-AF-related emergencies; and assessing and managing common (lower limb injuries, open wounds injuries, soft tissue injuries) and uncommon but serious (an unconscious casualty, airway or respiratory distress) community-AF-related injuries. This is consistent with a risk assessment/management approach where the high-frequency (or likelihood), low or medium consequence injuries and low-frequency, severe consequence injuries are given highest priority. ${ }^{19}$

The fact that no consensus was reached on 26 competencies is also important and suggests that the panel considered it desirable but not necessary for community-AF sports trainers to have these competencies, and they could therefore legitimately be considered 'optional' in any education structure. These competencies tended to be those more related to: assessing and managing non-community-AF-related injuries that happen infrequently in a community-AF setting (eg, burns 
Table 6 Delphi survey 3 responses about sports trainers' competencies related to taping $(n=16)$

\begin{tabular}{|c|c|c|c|c|c|}
\hline Competency number and name & Consensus (\%) & Essential (n) & Expected (n) & Ideal (n) & Not required (n) \\
\hline \multicolumn{6}{|c|}{ A sports trainer involved with a community Australian Football club should be competent in taping } \\
\hline (47) Ankles & 93 & 13 & 2 & 1 & 0 \\
\hline (48) Thumbs & 93 & 13 & 2 & 1 & 0 \\
\hline (49) Fingers & 93 & 13 & 2 & 1 & 0 \\
\hline (50) Shoulders & 75 & 11 & 1 & 4 & 0 \\
\hline (51) Knees & 75 & 11 & 1 & 4 & 0 \\
\hline
\end{tabular}

Table 7 Delphi survey responses to sports trainers' competencies related to injury prevention and risk management $(n=15)$

\begin{tabular}{|c|c|c|c|c|c|}
\hline Competency number and name & Consensus (\%) & Essential (n) & Expected (n) & Ideal (n) & Not required (n) \\
\hline \multicolumn{6}{|c|}{ A sports trainer involved with a community-AF club should be competent and knowledgeable in Injury Prevention and Risk Management including } \\
\hline (53) Return to play & 86 & 8 & 5 & 2 & 0 \\
\hline (54) Massage & 80 & 6 & 6 & 3 & 0 \\
\hline (55) Fluid replacement & 73 & 6 & 5 & 3 & 1 \\
\hline (56) Protective equipment & 60 & 2 & 7 & 6 & 0 \\
\hline (57) Stretching & 60 & 2 & 7 & 6 & 1 \\
\hline (60) Recovery & 47 & 2 & 5 & 6 & 2 \\
\hline $\begin{array}{l}\text { (61) Working with specific population groups - children, mature ath- } \\
\text { letes, adolescents, athletes with a disability and female athletes }\end{array}$ & 40 & 3 & 3 & 8 & 1 \\
\hline (62) Drugs in sport & 40 & 2 & 4 & 6 & 3 \\
\hline (63) Playing environment - playing surface and goal posts & 33 & 1 & 4 & 6 & 4 \\
\hline (64) Nutrition & 33 & 0 & 5 & 6 & 4 \\
\hline (68) Strength and conditioning & 27 & 0 & 4 & 7 & 4 \\
\hline $\begin{array}{l}\text { (69) Contraindications of participation with infectious diseases and } \\
\text { medical conditions }\end{array}$ & 27 & 2 & 2 & 10 & 1 \\
\hline (70) Modified sports equipment & 20 & 0 & 3 & 9 & 3 \\
\hline
\end{tabular}

__ _ represents the cutoff point of $\geq 75 \%$ of respondents rating a competency as Essential or Expected, above which a competency was accepted as 'required' by a sports trainer to effectively perform the activities required to the standards expected at a community-AF club.

AF, Australian Football.

Table 8 Delphi survey 3 responses to sports trainers' competencies related to health promotion $(n=15)$

\begin{tabular}{|c|c|c|c|c|c|}
\hline $\begin{array}{l}\text { Competency number } \\
\text { and name }\end{array}$ & $\begin{array}{l}\text { Consensus } \\
(\%)\end{array}$ & Essential & Expected & Ideal & $\begin{array}{l}\text { Not } \\
\text { required }\end{array}$ \\
\hline
\end{tabular}

A sports trainer involved with a community-AF club should be competent and knowledgeable in

\begin{tabular}{llllll} 
(71) Alcohol & 47 & 3 & 4 & 4 & 4 \\
(72) Sports psychology & 27 & 0 & 4 & 7 & 4 \\
(73) Burns & 27 & 1 & 3 & 7 & 4 \\
\hline (74) Fair play & 13 & 1 & 1 & 6 & 7 \\
(75) Skill development & 7 & 0 & 1 & 5 & 9 \\
(76) Drowning & 7 & 0 & 1 & 7 & 7 \\
(77) Equity in & 7 & 0 & 1 & 4 & 10 \\
\multicolumn{1}{c}{ participation } & & & & & \\
\hline
\end{tabular}

_ represents the cutoff point of $\geq 75 \%$ of respondents rating a competency as Essential or Expected, above which a competency was accepted as 'required' by a sports trainer to effectively perform the activities required to the standards expected at a community-AF club.

represents the cutoff point of $\geq 85 \%$ of respondents rating a competency as $\overline{\text { Ideal }}$ or Not Required, below which a competency was accepted as 'not required' by a sports trainer to effectively perform the activities required to the standards expected at a community-AF club.

$\mathrm{AF}$, Australian Football. and stings; extremes of temperature); injury prevention (eg, preparticipation medical history and information; protective equipment and playing environment); player performance (eg, warm up and cool down; strength and conditioning); and the promotion of positive health (eg, nutrition; drugs; alcohol). The two community-AF-specific competencies in the Injury and Illness Assessment and Immediate Management category that were not considered 'required' may have been rated this way because trunk injuries are relatively uncommon in community-AF and overuse/chronic injuries are generally slow onset and less relevant to first-aid.

The panel members also agreed that four competencies (related to competence in drowning, fair play, skill development and equity in participation) were 'not required' and therefore could justifiably be removed from any education structure. It is likely that these competencies were rated this way because it is almost inconceivable that they would happen in a community-AF setting (in the case of drowning) or they are clearly the responsibility of others (coaches, umpires, administrators, etc.).

There has been considerable interest in using community sport to promote health..$^{20-22}$ Although it has not been suggested that sports trainers/first-aid providers should be 

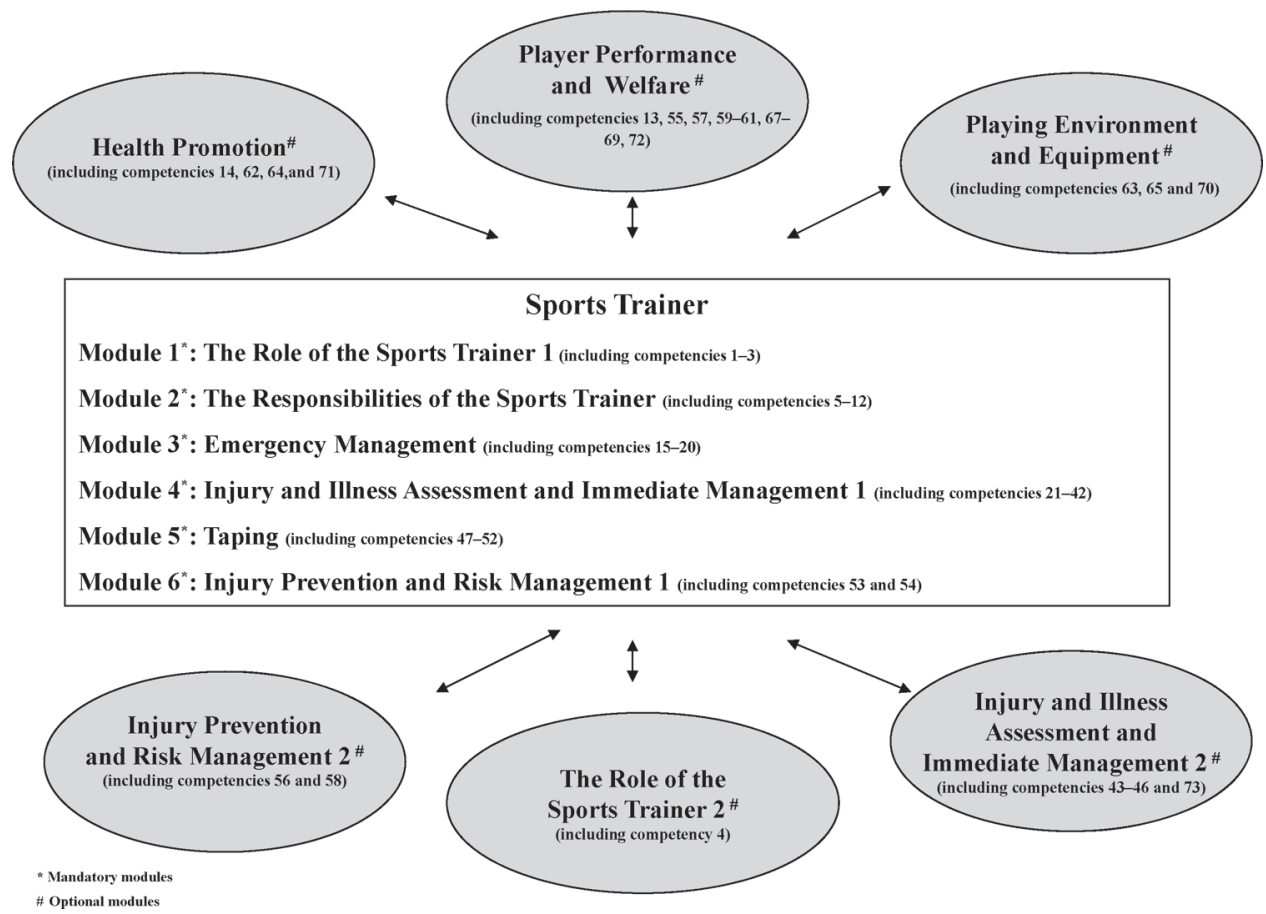

Figure 2 Proposed community Australian Football-specific sports trainer education course.

responsible for health promotion-related activities, because there are limited numbers of volunteers in community sporting organisations, sports trainers could be targeted to take on this role. Panel members in this study did not believe that the sports trainer role should include health promotion-related activities. Those advocating for health promoting community sports clubs will need to either negotiate with sports trainers to undertake this role or identify others to fulfil this role.

The most important outcome of this study is that community-AF sports trainer educators can now match their course content to the competencies that sports trainers need. This should minimise the risk of the education being irrelevant and potentially too expensive or time consuming. The study findings should also be used to ensure that any AFL first-aidrelated policies for community-AF do not place unnecessary demands on sports trainers that will make them unwilling to take on the role.

It can be a challenge to recruit and retain expert panel participants using the Delphi method ${ }^{14}$ because of the continued commitment required from participants who are repeatedly questioned about the same topic, using a slightly modified questionnaire. Although the iterative nature of the Delphi method allows panel members to reflect on and alter their responses on the basis of anonymous feedback from others, ${ }^{23}$ it can also lead to substantial attrition among panellists between the start and the end of the process. ${ }^{18}$ One of the strengths of this study was the high level of initial engagement (89\% of invited experts participated) and retention (100\%) of experts. We can only speculate that the research topic; endorsement and active support of the sport's governing body; convenience of the online survey process; quick processing, summarising and recirculating of early-round survey data; and the engagement of end users in the early stages of policy research, all contributed to motivating the experts to engage and continue with participation in this study. A second major strength was the high level of relevant background possessed by the 16 panel members with over $50 \%$ self-reporting 'a lot' or 'very extensive' to all 10 categories included in the background questionnaire.

A number of limitations of this study need to be acknowledged. First, it may have been difficult for panel members to interpret the meaning of and distinguish between some overlapping competencies (eg, safety, risk management and injury prevention in the Role and Importance category). Second, the list of competencies included both 'knowledge' (eg, understanding the role of a sports trainer) and 'skill' (eg, being able to perform cardiopulmonary resuscitation) based competencies and panel members might have had difficulty comparing and rating these different types of competencies. Third, some competencies were more abstract in nature (eg, 'health promotion' and 'equity in participation') and panel members might not have understood these as well as they understood other, more specific and objective competencies (eg, 'ankle' taping and immediate management of 'bleeding'). In addition, the standard required for a sports trainer to be considered competent was not considered in this study, and it is possible that different panel members may have interpreted this differently. Finally, the definition of community-AF used in this study was broad and included well-resourced state-league and large metropolitan clubs alongside less well-resourced smaller rural clubs, and clubs with senior players alongside clubs with junior players. Previous research suggests that it is difficult to develop standards (or in this case competencies) that are relevant and applicable across all types of community sporting organisations and all levels of competition. ${ }^{20}$

\section{CONCLUSION}

The competencies considered required by community-AF sports trainers include those related to understanding their roles and responsibilities, recognising and appropriately managing emergencies, assessing and immediately managing community-AFspecific common and potentially serious injuries and taping commonly injured joints. The expert consensus is that it is 


\section{What is already known on this topic}

- Providing first-aid is a fundamental risk management strategy for most sports.

- Generic sports first-aid and sports trainer education courses are available, but these are not generally tailored to the needs of specific sports.

\section{What this study adds}

- To meet the context-specific requirements, community Australian Football (community-AF) sports trainer education should focus on ensuring that participants are competent in recognising and appropriately managing emergencies, assessing and immediately managing community-AFspecific common and potentially serious injuries and taping commonly injured joints.

- To avoid overburdening participants, optional community-AF sports trainer education should focus on: health promotion; player performance and welfare; playing environment and equipment; injury prevention and risk management; and the assessment and immediate management of common nonAF-related injuries and illnesses.

- The Delphi method is a useful and manageable research process for gaining expert consensus among community sport administrators and service providers.

desirable rather than necessary for community-AF sports trainers to be competent in risk management, injury prevention, health promotion and the assessment and immediate management of non-community-AF-related injuries and illnesses.

Contributors Both authors contributed to the conception and design of the study, the analysis and interpretation of the data, drafting the article and revising it critically for important intellectual content. Both authors provided final approval of the version to be published.

Acknowledgements The project was conducted through an active collaboration between the AFL and the researchers. The AFL members of the project team were as follows: Mr Lawrie Woodman (Manager Coaching, Umpiring and Volunteers), Mr Peter Romaniw (Community Development Coordinator), Dr Hugh Seward (AFL Medical Officers Association) and Mr Nick Ames (Consultant physiotherapist to AFL Junior Development Program). The study was conducted when the two authors were employed at the University of Ballarat, and the paper write-up occurred when they were employed at Monash University. The project would not have been possible without the dedication and commitment of the experts who participated in the Delphi process.

Funding This project was funded by a grant from the Australian Football League (AFL) Research Board. CFF was supported by an NHMRC Principal Research
Fellowship (ID: 565900). AD was funded by the AFL grant during the conduct phase and an NHMRC Project Grant (ID: 565907) during the write-up phase.

\section{Competing interests None.}

Ethics approval The study was approved by the University of Ballarat Human Research Ethics Committee.

Provenance and peer review Not commissioned; externally peer reviewed.

\section{REFERENCES}

1. McManus A, Stevenson M, Finch CF, et al. Incidence and risk factors for injury in non-elite Australian Football. J Sci Med Sport 2004;7:384-91.

2. Braham R, Finch CF, McIntosh A, et al. Community level Australian Football: a profile of injuries. J Sci Med Sport 2004;7:96-105.

3. Gabbe B, Finch C, Wajswelner $\mathrm{H}$, et al. Australian football: injury profile at the community level. J Sci Med Sport 2002;5:149-60.

4. Gabbe BJ, Finch CF. Injury countermeasures in Australian Football. J Sci Med Sport 2000;3(2 Supp 1):31-40.

5. Finch CF, McGrath A. SportSafe Australia: A National Sports Safety Framework. A report prepared for the Australian Sports Injury Prevention Taskforce. Canberra, ACT: Australian Sports Commission, 1997:56-7.

6. Zazryn T, Finch C, Garnham A. Is safety a priority for football clubs? Sport Health 2004;21:19-24.

7. Casey M, Finch CF, Mahoney M, et al. Sport safety policies and practices in two rural Victorian communities. J Sci Med Sport 2004;7:226-31.

8. Donaldson A, Forero R, Finch CF. The first aid policies and practices of community sports clubs in northern Sydney, Australia. Health Promot J Austr 2004;15:156-62.

9. Finch CF, Hennessy M. The safety practices of sporting clubs/centres in the city of Hume. J Sci Med Sport 2000;3:9-16.

10. Donaldson A, Forero R, Finch CF, et al. A comparison of the sports safety policies and practices of community sports clubs during training and competition in northern Sydney, Australia. Br J Sports Med 2004;38:60-3.

11. Cunningham $\mathbf{A}$. An audit of first aid qualifications and knowledge among team officials in two English youth football leagues: a preliminary study. Br J Sports Med 2002;36:295-300.

12. Abernethy L, MacAuley D, McNally 0 , et al. Immediate care of school sport injury. Inj Prev 2003;9:270-3.

13. Vangsness CT Jr, Hunt T, Uram M, et al. Survey of health care coverage of high school football in southern California. Am J Sports Med 1994;22:719-22.

14. Hasson F, Keeney S, McKenna H. Research guidelines for the Delphi survey technique. J Adv Nurs 2000;32:1008-15.

15. Katcher ML, Meister AN, Sorkness CA, et al. Use of the modified Delphi technique to identify and rate home injury hazard risks and prevention methods for young children. Inj Prev 2006;12:189-94.

16. Kennedy HP. Enhancing Delphi research: methods and results. J Adv Nurs 2004:45:504-11.

17. Williams PL, Webb C. The Delphi technique: a methodological discussion. J Adv Nurs 1994;19:180-6.

18. Keeney S, Hasson F, McKenna H. Consulting the oracle: ten lessons from using the Delphi technique in nursing research. J Adv Nurs 2006;53:205-12.

19. Fuller CW, Ward CJ. An empirical approach for defining acceptable levels of risk: a case study in team sports. Inj Prev 2008;14:256-61.

20. Kokko S, Kannas L, Villberg J. Health promotion profile of youth sports clubs in Finland: club officials' and coaches' perceptions. Health Promot Int 2009;24:26-35.

21. Eime RM, Payne WR, Harvey JT. Making sporting clubs healthy and welcoming environments: a strategy to increase participation. J Sci Med Sport 2008; 11:146-54

22. Kelly B, Baur LA, Bauman AE, et al. Health promotion in sport: an analysis of peak sporting organisations' health policies. J Sci Med Sport 2010;13:566-7.

23. Crisp J, Pelletier D, Duffield C, et al. The Delphi method? Nurs Res 1997;46:116-18. 